Caracterização e localização dos pontos notáveis do triângulo

Elvis Donizeti Neves 
SERVIÇO DE PÓS-GRADUAÇÃO DO ICMC-USP

Data de Depósito:

Assinatura:

\title{
Caracterização e localização dos pontos notáveis do triângulo
}

\author{
Elvis Donizeti Neves \\ Orientador: Prof. Dr. Hermano de Souza Ribeiro \\ Dissertação apresentada ao Instituto de Ciências \\ Matemáticas e de Computação - ICMC-USP, como \\ parte dos requisitos para obtenção do título de Mestre \\ em Ciências - Programa de Mestrado Profissional em \\ Matemática. VERSÃ O REVISADA
}


Ficha catalográfica elaborada pela Biblioteca Prof. Achille Bassi e Seção Técnica de Informática, ICMC/USP, com os dados fornecidos pelo(a) autor(a)

N499c $\begin{aligned} & \text { Neves, Elvis Donizeti } \\ & \text { Caracterização e Localização dos Pontos Notáveis } \\ & \text { do Triângulo / Elvis Donizeti Neves; orientador } \\ & \text { Hermano de Souza Ribeiro. -- São Carlos, 2013. } \\ & 71 \text { p. } \\ & \text { Dissertação (Mestrado - Programa de Pós-Graduação } \\ & \text { em Mestrado Profissional em Matemática em Rede } \\ & \text { Nacional) -- Instituto de Ciências Matemáticas e de } \\ & \text { Computação, Universidade de São Paulo, 2013. } \\ & \text { 1. Triângulos. 2. Sistema Cartesiano. 3. Números } \\ & \text { Complexos. 4. Pontos Notáveis do Triângulo. I. } \\ & \text { Ribeiro, Hermano de Souza, orient. II. Título. }\end{aligned}$


Dedico esta dissertação à minha amada esposa, à minha irmã, minha mãe e aos meus sogros, com amor, carinho e gratidão por todo o apoio. 


\section{AGRADECIMENTOS}

- A Deus, por me sustentar em todo o tempo e me capacitar.

- À minha amada esposa Cecilia, por me alavancar nos momentos mais difíceis, por exigir sempre o meu melhor e por me mostrar como tirar grandes lições dos momentos difíceis que por vezes assolam nossas vidas.

- À minha querida irmã Letícia, que sempre me acompanhou e apoiou todas as minhas iniciativas.

- À minha mãe Luiza e aos meus sogros Marta e Militão, pelo auxílio emocional e incentivo.

- Ao Prof.․ Dr. Hermano de Souza Ribeiro, por compartilhar comigo sua magnífica experiência e conhecimento, pela orientação e confiança, pelo constante apoio, e, sobretudo, pela sua amizade.

- Ao pessoal do mestrado, turma de 2011.

- E a todos os meus amigos que colaboraram para a realização deste trabalho. 

"A matemática é o alfabeto pelo qual Deus escreveu o universo."

Galileo Galilei (1564-1642) - tradução própria 


\section{RESUMO}

NEVES, E. D. Caracterização e localização dos pontos notáveis do triangulo. 2013. 71f. Dissertação (Mestrado) - Instituto de Ciências Matemáticas e de Computação, Universidade de São Paulo, São Carlos, 2013

O ensino de Matemática é, de modo geral, orientado pelos processos contidos nos livros didáticos. Sendo assim, a organização dos conceitos matemáticos nesses livros deveria ser capaz de permitir ao leitor interpretar a Matemática em sua essência, admitindo o estabelecimento de relações entre os conteúdos. No entanto, o que geralmente se observa nos materiais é um aglomerado de definições e conceitos desconexos que conduzem o leitor a dificuldades de aprendizado na área. Por essa razão, a presente dissertação teve o objetivo principal de localizar, além de caracterizar, os pontos notáveis do triângulo: o centróide ou baricentro $(G)$, o ortocentro $(H)$, 0 circuncentro $(\mathrm{O})$, o centro $(\mathrm{N})$ da circunferência de nove pontos, os três ex-centros das circunferências ex-inscritas, as projeções ortogonais dos vértices sobre os lados opostos e os pontos de tangência da circunferência inscrita e ex-inscrita. Quatro abordagens são apresentadas em busca de tal objetivo: a-) apresentar a geometria do triângulo segundo técnicas de percepção visual; b-) caracterizar alguns pontos notáveis do triângulo, como pontos de máximo ou de mínimo de funções com as demonstrações utilizando desigualdade de Cauchy-Schwarz e entre média aritmética e geométrica; c-) utilizar um sistema cartesiano adequado para o cálculo das abscissas e ordenadas do centróide $(\mathrm{G})$, do ortocentro $(\mathrm{H})$ e do circuncentro $(\mathrm{O})$ de um triângulo; d-) utilizar os números complexos para a completa localização de todos os pontos notáveis do triângulo além de apresentar a equação da reta de Euler, o incentro (I) e os três excentros $I_{A}, I_{B}$ e $I_{C}$ localizados em fórmulas simples. A dissertação finaliza com 0 Teorema de Feuerbach, apresentado com uma prova elementar, mostrando que a circunferência de nove pontos e a circunferência inscrita são tangentes internamente e que a circunferência dos nove pontos é tangente exteriormente a cada uma das três ex circunferências e o Teorema de Napoleão, no qual os baricentros de triângulos equiláteros, construídos a partir dos lados de um triângulo qualquer, formam um outro triângulo equilátero. Comparando as várias abordagens da dissertação, a conclusão é a de que a compreensão dos números complexos paradoxalmente simplifica a resolução de problemas de geometria plana e a solução de equações polinomiais. Assim, acredita-se que uma maior exploração desse conteúdo no ensino da Matemática poderia tornar o aprendizado mais atraente e simplificado.

Palavras-chave: triângulos, sistema cartesiano, números complexos, pontos notáveis do triângulo. 


\begin{abstract}
NEVES, E. D. Characterization and location of the notable points of the triangle. 2013. 71f. Dissertação (Mestrado) - Instituto de Ciências Matemáticas e de Computação, Universidade de São Paulo, São Carlos, 2013

The teaching of Mathematics is generally guided by the procedures contained in the textbooks. Thus, the organization of the mathematical concepts in these books should be able to allow the reader to interpret the Mathematics in its essence, admitting the establishment of relationships between the contents. However, what is observed in the materials is a conglomeration of disparate definitions and concepts that lead the reader to learning difficulties in the area. For this reason, this work aimed to locate and characterize the notable points of the triangle: the centroid or barycenter $(\mathrm{G})$, the orthocenter $(\mathrm{H})$, the circumcenter $(\mathrm{O})$, the center $(\mathrm{N})$ of circumference of nine points, three former centers of the ex-inscribed circles, orthogonal projections of the vertices on the opposite sides and the points of tangency of the inscribed and the ex-inscribed circumference. Four approaches are presented to achieve these goals: a-) to introduce the geometry of the triangle using visual perception techniques, b-) to characterize some notable points of the triangle, as points of maximum or minimum of functions with the demonstrations using the Cauchy-Schwarz inequality and between the arithmetic and geometric mean;-c) to use a suitable Cartesian system for calculating the abscissas and ordinates of the centroid $(G)$, of orthocenter $(H)$ and of the circumcenter $(O)$ of a triangle;-d) to use complex numbers for the complete location of all notable points of the triangle, beyond depicting the Euler equation of the line, the incenter (I) and the three former centers $I_{A}, I_{B}$ and $I_{C}$ located in simple formulas. The work is concluded with the Feuerbach's Theorem, presented with an elementary proof, showing that the nine-point circle and the incircle is tangent internally and that the circumference of the nine points is externally tangent to each of the three ex-inscribed circles and the Napoleon's Theorem, in which the barycenters of equilateral triangles, constructed from the sides of any triangle, form another equilateral triangle. Comparing the approaches detached hitherto, the conclusion is that the understanding of complex numbers paradoxically simplifies troubleshooting of plane geometry and the solution of polynomial equations. Thus, it is believed that further exploration of this content in mathematics education could make learning more attractive and simplified.
\end{abstract}

Keywords: triangles, Cartesian system, complex numbers, notable points of the triangle. 



\section{SUMÁRIO}

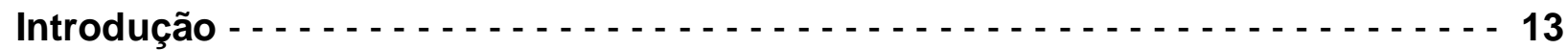

1 Demonstrações Sucintas das Fórmulas da Geometria do Triângulo - - - - - - - - 19

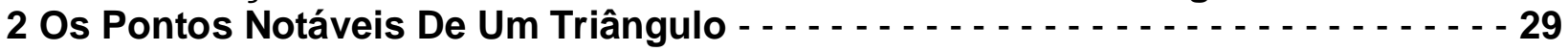

2.1 Caracterização do Incentro (I) do Triângulo ABC como ponto de máximo - - - - 30

2.2 Caracterização do Incentro (I) do Triângulo ABC como ponto de mínimo - - - - 32

2.3 Caracterização do Centróide $(G)$ do Triângulo ABC como ponto de máximo - - 33

3 Coordenadas Cartesianas Dos Pontos Notáveis De Um Triangulo - - - - - - - - - - 37

3.1 Cálculo das Distâncias entre os Pontos Colineares - Ortocentro, Circuncentro e Centróide - . . . . . . . . . . . . . . . . . . . . . . . . . . . . . 43

4 Os Pontos Notáveis De Um Triangulo Como Números Complexos - - - - - - - - - 47

4.1 Condição de Alinhamento de Três Pontos $(A, B, C)$ no Plano Complexo com Coordenadas $A\left(X_{a}, Y_{a}\right) B\left(X_{b}, Y_{b}\right)$ e $C\left(X_{c}, Y_{c}\right) \ldots \ldots$

4.2 Equação da Reta Mediatriz dos Números Complexos Distintos A e B- - - - - - 50

4.3 Equação do Feixe de Retas Perpendiculares no Plano Complexo a Uma Reta Dada

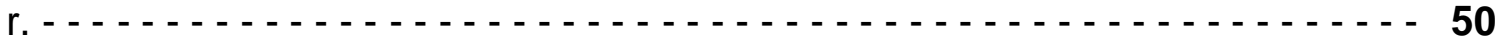

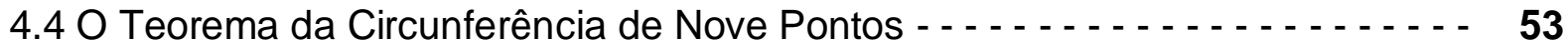

4.5 Equação da Reta Determinada por dois Números Complexos Distintos A e B - 57

4.6 Equações no Plano Complexo das Retas Notáveis do Triângulo Determinado Por

Três Números Complexos Distintos e Não Colineares A, B e C - - - . - - - - - 58

4.7 Equações das Três Bissetrizes Internas e das Três Bissetrizes Externas do Triângulo Determinado Por Três Números Complexos Não Colineares Distintos $A^{2}$, $\mathrm{B}^{2}$ e $\mathrm{C}^{2} \ldots \ldots \ldots \ldots$

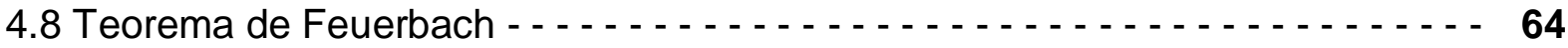

4. 9 Teorema de Napoleão- $\ldots \ldots \ldots 7$

5 Conclusões - _ $\ldots \ldots \ldots$

6 Referências $\ldots \ldots \ldots \ldots$ 



\section{Introdução}

No âmbito escolar atual, o ensino de Matemática para alunos do Ensino Fundamental e Médio é considerado, de modo geral, bastante problemático, uma vez que resultados insatisfatórios têm sido registrados pelo sistema de Avaliação de Rendimento Escolar do Estado de São Paulo (SARESP ${ }^{1}$ ) e pelo Índice de Desenvolvimento da Educação Básica $\left(\right.$ IDEB $\left.^{2}\right)$ nos últimos anos. Isso ocorre em grande parte devido à organização dos conteúdos nos livros didáticos e materiais apostilados, que muitas vezes propiciam aos alunos um caminho errôneo de interpretação da Matemática por não apresentarem relações entre os conteúdos. Desenvolvidos para facilitar o ensino de Matemática, estes materiais acabam por fragmentá-la, tornando-a um aglomerado de definições desconexas.

Preocupada com o ensino da Matemática no Estado de São Paulo, a Secretaria de Educação do Estado de São Paulo lançou uma Proposta Curricular reformulada ${ }^{3}$, cuja divisão dos conteúdos pode ser visualizada nas Tabelas 1 e 2 , para o ensino fundamental - Ciclo II e para o Ensino Médio, respectivamente. Embora tal divisão seja bem abrangente, um dos conteúdos, a saber, a Geometria, poderia ser mais bem explorada e relacionada com outras áreas do conhecimento. Pesquisas sobre o aprendizado de Geometria constatam que essa é uma área da Matemática que apresenta resultados consideravelmente insatisfatórios, uma vez que é menos explorada do que outras áreas da matemática, tal como a Álgebra, não somente nas séries iniciais da Educação básica, mas também no Ensino fundamental - Ciclo II e no Ensino Médio. Além disso, como pode ser verificado nas Tabelas 1 e 2, a Geometria, é muitas vezes, abordada sem integração com outros conteúdos matemáticos, dificultando o estabelecimento de relações entre eles ${ }^{4-6}$. 
Porém, isto tem mudado com a implantação do Plano Nacional do Livro Didático

(PNLD).

Tabela 1. Conteúdos de Matemática por série e bimestre do Ensino Fundamental (Ciclo II), segundo a Proposta Curricular para o Estado de São Paulo ${ }^{3}$.

\begin{tabular}{|c|c|c|c|c|}
\hline & 5'a SÉRIE & 6? SÉRIE & $7^{7^{a} \text { SÉRIE }}$ & 8 SÉRIE $^{\text {a }}$ \\
\hline $\begin{array}{l}B \\
\text { I } \\
\text { M } \\
\text { E } \\
\text { S } \\
\text { T } \\
\text { R } \\
\text { E }\end{array}$ & $\begin{array}{l}\text { Números naturais } \\
\text { - Múltiplos e divisores. } \\
\text { - Números primos. } \\
\text { - Operações básicas } \\
(+,-, x, \div) \\
\text { - Introdução às } \\
\text { potencias. } \\
\text { Frações } \\
\text { - Representação. } \\
\text { - Comparação e } \\
\text { ordenação. } \\
\text { - Operações. }\end{array}$ & $\begin{array}{l}\text { Sistemas de numeração } \\
\text { - Sistemas de numeração } \\
\text { na Antiguidade. } \\
\text { - Sistema posicional } \\
\text { decimal. } \\
\text { Números negativos } \\
\text { - Representação. } \\
\text { - Operações. } \\
\text { Números racionais } \\
\text { - Representação } \\
\text { fracionaria e decimal. } \\
\text { - Operações com } \\
\text { decimais } \\
\text { e frações } \\
\text { (complementos). }\end{array}$ & $\begin{array}{l}\text { Números racionais } \\
\text { - Transformação } \\
\text { de decimais } \\
\text { finitos em frações. } \\
\text { - Dízimas periódicas } \\
\text { e fração geratriz. } \\
\text { Potenciação } \\
\text { - Propriedades para } \\
\text { expoentes inteiros. } \\
\text { - Problemas de } \\
\text { contagem. }\end{array}$ & $\begin{array}{l}\text { Números reais } \\
\text { - Conjuntos } \\
\text { numéricos. } \\
\text { - Números } \\
\text { irracionais. } \\
\text { - Potenciação e } \\
\text { radiciação em } \mathbb{R} \text {. } \\
\text { - Notação cientifica. }\end{array}$ \\
\hline $\begin{array}{l}B \\
\text { I } \\
\text { M } \\
\text { E } \\
\text { S } \\
\text { T } \\
\text { R } \\
\text { E }\end{array}$ & $\begin{array}{l}\text { Números decimais } \\
\text { - Representação. } \\
\text { - Transformação em } \\
\text { fração decimal. } \\
\text { - Operações. } \\
\text { Sistemas de medida } \\
\text { - Medidas de } \\
\text { comprimento, massa e } \\
\text { capacidade. } \\
\text { - Sistema métrico } \\
\text { decimal: múltiplos e } \\
\text { submúltiplos da } \\
\text { unidade. }\end{array}$ & $\begin{array}{l}\text { Geometria } \\
\text { - Ângulos. } \\
\text { - Polígonos. } \\
\text { - Circunferência. } \\
\text { - Simetrias. } \\
\text { - Construções } \\
\text { geométricas. } \\
\text { - Poliedros. }\end{array}$ & $\begin{array}{l}\text { Expressões } \\
\text { algébricas } \\
\text { - Equivalências e } \\
\text { transformações. } \\
\text { - Produtos notáveis. } \\
\text { - Fatoração } \\
\text { algébrica. }\end{array}$ & $\begin{array}{l}\text { Algebra } \\
\text { - Equações do } 2^{\circ} \\
\text { grau: resolução e } \\
\text { problemas. } \\
\text { Funções } \\
\text { - Noções básicas } \\
\text { sobre função. } \\
\text { - A ideia de } \\
\text { variação. } \\
\text { - Construção de } \\
\text { tabelas e gráficos } \\
\text { para representar } \\
\text { funções de } 1^{\circ} \text { e } 2^{\circ} \\
\text { graus. }\end{array}$ \\
\hline $\begin{array}{l}B \\
\text { I } \\
\text { M } \\
\text { E } \\
\text { S } \\
\text { T } \\
\text { R } \\
\text { E }\end{array}$ & $\begin{array}{l}\text { Formas geométricas } \\
\text { - Formas planas. } \\
\text { - Formas espaciais. } \\
\text { Perímetro e área } \\
\text { - Unidades de medida. } \\
\text { - Perímetro de uma } \\
\text { figura plana. } \\
\text { - Calculo de área por } \\
\text { composição e } \\
\text { decomposição. } \\
\text { - Problemas envolvendo } \\
\text { área e perímetro de } \\
\text { figuras planas. }\end{array}$ & $\begin{array}{l}\text { Proporcionalidade } \\
\text { - Variação de grandezas } \\
\text { diretamente ou } \\
\text { inversamente } \\
\text { proporcionais. } \\
\text { - Conceito de razão. } \\
\text { - Porcentagem. } \\
\text { - Razões constantes na } \\
\text { geometria: } \pi \text {. } \\
\text { - Construção de gráficos } \\
\text { de setores. } \\
\text { - Problemas envolvendo } \\
\text { probabilidade. }\end{array}$ & $\begin{array}{l}\text { Equações } \\
\text { - Resolução de } \\
\text { equações de 1ำ } \\
\text { grau. } \\
\text { - Sistemas de } \\
\text { equações e } \\
\text { resolução de } \\
\text { problemas. } \\
\text { - Inequações do } 10 \\
\text { grau. } \\
\text { Gráficos } \\
\text { - Coordenadas: } \\
\text { localização de } \\
\text { pontos no plano } \\
\text { cartesiano. }\end{array}$ & $\begin{array}{l}\text { Proporcionalidade } \\
\text { na geometria } \\
\text { - O conceito de } \\
\text { semelhança. } \\
\text { - Semelhança de } \\
\text { triângulos. } \\
\text { - Razões } \\
\text { trigonométricas. }\end{array}$ \\
\hline $\begin{array}{c}\text { B } \\
\text { I } \\
\text { M } \\
\text { E }\end{array}$ & $\begin{array}{l}\text { Estatística } \\
\text { - Leitura e construção } \\
\text { de gráficos e tabelas. } \\
\text { - Media aritmética. } \\
\text { - Problemas de } \\
\text { contagem. }\end{array}$ & $\begin{array}{l}\text { Álgebra } \\
\text { - Uso de letras para } \\
\text { representar um valor } \\
\text { desconhecido. } \\
\text { - Conceito de equação. } \\
\text { - Resolução de }\end{array}$ & $\begin{array}{l}\text { Geometria } \\
\text { - Teorema de Tales. } \\
\text { - Teorema de } \\
\text { Pitágoras. } \\
\text { - Área de polígonos. } \\
\text { - Volume do prisma. }\end{array}$ & $\begin{array}{l}\text { Corpos redondos } \\
\text { - O numero } \pi ; \text { a } \\
\text { circunferência, } \\
\text { o circulo e suas } \\
\text { partes; área do } \\
\text { circulo. }\end{array}$ \\
\hline
\end{tabular}




\begin{tabular}{|c|c|c|}
\hline $\begin{array}{l}\mathrm{S} \\
\mathbf{T} \\
\mathbf{R} \\
\mathrm{E}\end{array}$ & $\begin{array}{l}\text { equações. } \\
\text { Equações e } \\
\text { problemas. }\end{array}$ & $\begin{array}{l}\text { Volume e área do } \\
\text { cilindro. } \\
\text { Probabilidade } \\
\text { - Problemas de } \\
\text { contagem e } \\
\text { introdução à } \\
\text { probabilidade. }\end{array}$ \\
\hline
\end{tabular}

Tabela 2. Conteúdos de Matemática por série e bimestre do Ensino Fundamental, segundo a Proposta Curricular para o Estado de São Paulo ${ }^{3}$.

\begin{tabular}{|c|c|c|c|}
\hline & $1^{\text {a }}$ Série & $2^{\mathrm{a}}$ Série & 3aㅗ Série \\
\hline $\begin{array}{l}B \\
\text { I } \\
\text { M } \\
\text { E } \\
\text { S } \\
\text { T } \\
\text { R } \\
\text { E }\end{array}$ & $\begin{array}{l}\text { Números e sequencias } \\
\text { - Conjuntos numéricos. } \\
\text { - Regularidades numéricas: } \\
\text { sequências. } \\
\text { - Progressões aritméticas e } \\
\text { progressões geométricas. }\end{array}$ & $\begin{array}{l}\text { Trigonometria } \\
\text { - Fenômenos periódicos. } \\
\text { - Funções } \\
\text { trigonométricas. } \\
\text { - Equações e inequações. } \\
\text { - Adição de arcos. }\end{array}$ & $\begin{array}{l}\text { Geometria analítica } \\
\text { - Pontos: distância, ponto médio e } \\
\text { alinhamento de três pontos. } \\
\text { - Reta: equação e estudo dos } \\
\text { coeficientes; problemas lineares. } \\
\text { - Ponto e reta: distancia. } \\
\text { - Circunferência: equação. } \\
\text { - Reta e circunferência: posições } \\
\text { relativas. } \\
\text { - Cônicas: noções e aplicações. }\end{array}$ \\
\hline $\begin{array}{l}B \\
\text { I } \\
\text { M } \\
\text { E } \\
\text { S } \\
\text { T } \\
\text { R } \\
\text { E }\end{array}$ & $\begin{array}{l}\text { Funções } \\
\text { - Relação entre duas } \\
\text { grandezas. } \\
\text { - Proporcionalidades: } \\
\text { direta, inversa, direta com } \\
\text { o quadrado. } \\
\text { - Função de } 10 \text { grau. } \\
\text { - Função de } 20 \text { grau. }\end{array}$ & $\begin{array}{l}\text { Matrizes, determinantes } \\
\text { e sistemas lineares } \\
\text { - Matrizes: significado } \\
\text { como tabelas, } \\
\text { características e } \\
\text { operações. } \\
\text { - A noção de determinante } \\
\text { de uma matriz quadrada. } \\
\text { - Resolução e discussão } \\
\text { de sistemas lineares: } \\
\text { escalonamento. }\end{array}$ & $\begin{array}{l}\text { Equações algébricas } \\
\text { e números complexos } \\
\text { - Equações polinomiais. } \\
\text { - Números complexos: } \\
\text { operações e representação } \\
\text { geométrica. } \\
\text { - Propriedades das raízes de uma } \\
\text { equação polinomial. } \\
\text { - Relações de Girard. }\end{array}$ \\
\hline $\begin{array}{l}B \\
\text { I } \\
\text { M } \\
\text { E } \\
\text { S } \\
T \\
\text { R } \\
\text { E }\end{array}$ & $\begin{array}{l}\text { Funções exponencial } \\
\text { e logarítmica } \\
\text { - Crescimento exponencial. } \\
\text { - Função exponencial: } \\
\text { equações e inequações. } \\
\text { - Logaritmos: definição } \\
\text { e propriedades. } \\
\text { - Função logarítmica: } \\
\text { equações e inequações. }\end{array}$ & $\begin{array}{l}\text { Análise combinatória } \\
\text { e probabilidade } \\
\text { - Raciocínio } \\
\text { combinatório: princípios } \\
\text { multiplicativo e aditivo. } \\
\text { - Probabilidade simples. } \\
\text { - Casos de } \\
\text { agrupamentos: arranjos, } \\
\text { combinações e } \\
\text { permutações. } \\
\text { - Probabilidade da } \\
\text { reunião e/ou da } \\
\text { intersecção de eventos. } \\
\text { - Probabilidade } \\
\text { condicional. } \\
\text { - Distribuição binomial } \\
\text { de probabilidades: o } \\
\text { triângulo de Pascal e o } \\
\text { Binômio de Newton. }\end{array}$ & $\begin{array}{l}\text { Estudo das funções } \\
\text { - Qualidades das funções. } \\
\text { - Gráficos: funções trigonométricas, } \\
\text { exponencial, logarítmica e } \\
\text { polinomial. } \\
\text { - Gráficos: analise de sinal, } \\
\text { crescimento e taxa de variação. } \\
\text { - Composição: translações e } \\
\text { reflexões. } \\
\text { - Inversão. }\end{array}$ \\
\hline $\begin{array}{l}40 \\
\text { B } \\
\text { I } \\
\text { M }\end{array}$ & $\begin{array}{l}\text { Geometria- } \\
\text { Trigonometria } \\
\text { - Razões trigonométricas } \\
\text { nos triângulos retângulos. } \\
\text { - Polígonos regulares: } \\
\text { inscrição, circunscrição }\end{array}$ & $\begin{array}{l}\text { Geometria métrica } \\
\text { espacial } \\
\text { - Elementos de } \\
\text { geometria de posição. } \\
\text { - Poliedros, prismas e } \\
\text { pirâmides. }\end{array}$ & $\begin{array}{l}\text { Estatística } \\
\text { - Gráficos estatísticos: calculo e } \\
\text { interpretação de índices } \\
\text { estatísticos. } \\
\text { - Medidas de tendência central: } \\
\text { média, mediana e moda. }\end{array}$ \\
\hline
\end{tabular}




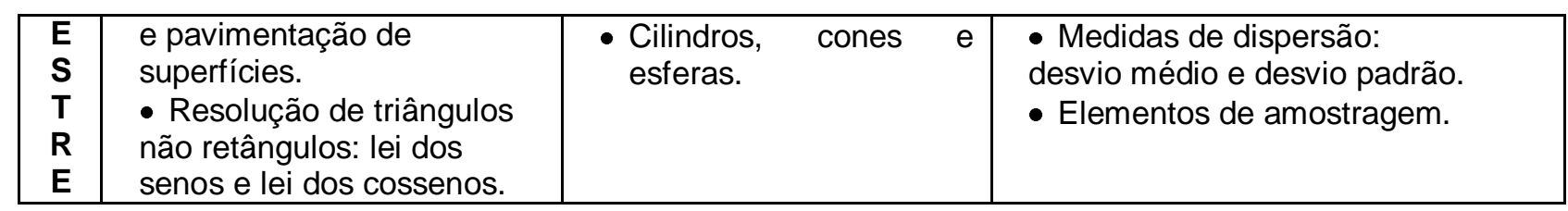

Por essa razão, na presente dissertação, procurei reunir em um volume único demonstrações de teoremas associados aos pontos notáveis de um triângulo no plano cartesiano e também no plano dos complexos. O plano cartesiano é vastamente utilizado em diferentes áreas da Matemática e por isso começo introduzindo, no Capítulo 1, alguns resultados clássicos da geometria do triângulo segundo técnicas de percepção visual; para completude, um elenco de fórmulas são mostradas. Em seguida, no Capítulo 2, caracterizo alguns pontos notáveis do triângulo, como pontos de máximo ou de mínimo de funções com as demonstrações utilizando desigualdade de Cauchy-Schwarz e entre média aritmética e geométrica. No Capítulo 3, utilizo um sistema cartesiano adequado para o cálculo das abscissas e ordenadas do centróide $(G)$, do ortocentro $(H)$ e do circuncentro $(O)$ de um triângulo. No Capítulo 4, utilizo os números complexos para a completa localização de todos os pontos notáveis do triângulo além de apresentar a equação da reta de Euler, o incentro $(I)$ e os três ex-centros $I_{A}$, $I_{B}$ e $I_{C}$ (de difícil localização no capítulo anterior), que são agora localizados em fórmulas simples. Finalizo o trabalho com os Teoremas de Feuerbach e de Napoleão, apresentando-o com uma prova elementar, mostrando que a circunferência de nove pontos e a circunferência inscrita são tangentes internamente e que a circunferência dos nove pontos é tangente exteriormente a cada uma das três circunferências ex-inscritas. Para maiores informações referentes aos desenvolvimentos matemáticos apresentados aqui, segure-se consultar as referências [7] a [11]. 
A geometria com os números complexos, embora estudada, fica geralmente restrita a apenas um tópico apresentado no segundo bimestre da proposta curricular da 3a série do Ensino Médio (ver Tabela 2). A aplicação dos números complexos pode ser vista em geometria, de modo que seu ensino pode ser simplificado se essa aplicação for mais bem explorada com os alunos, uma vez que a contextualização da matemática é fator decisivo na sua aprendizagem.

Vale ressaltar que uma das vantagens em se utilizar os números complexos é que as fórmulas dos pontos encontrados são mais simples em relação aos pontos encontrados no sistema cartesiano. A simplicidade dos números complexos tornam as demonstrações mais claras e rápidas.

É possível utilizar as ferramentas da geometria analítica e das variáveis complexas para facilitar o entendimento do estudo de geometria plana, particularmente o estudo de triângulos? 


\section{CAPÍTULO 1}

\section{Demonstrações sucintas das fórmulas da geometria do}

\section{triângulo}

Neste capítulo apresentaremos os pré-requisitos que serão utilizados nos capítulos seguintes e alguns resultados relacionados com a geometria do triângulo.

Neste trabalho serão adotadas as seguintes notações:

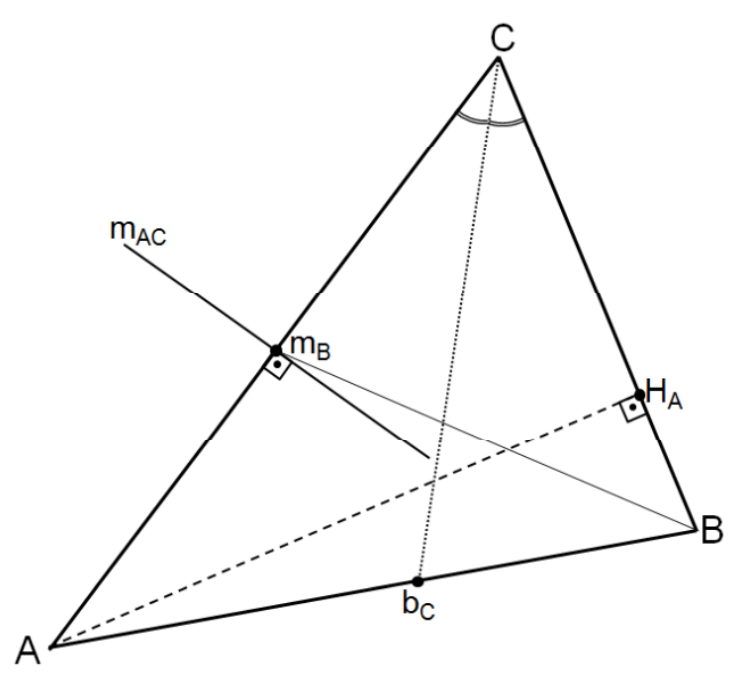

$(A B C)$ - área do triângulo $\triangle A B C$

$H_{X}$ - altura referente ao vértice $X$

$m_{X Y}-$ mediatriz do lado $X Y$

$m_{X}$ - mediana relativa ao vértice $X$

$b_{X}$ - bissetriz interna do vértice $X$

$x$ - medida do lado oposto ao vértice $X$

$p$-semi perímetro do triângulo

$\hat{X}$ - ângulo interno do vértice $X$

Figura 1. Alguns elementos de um triângulo.

\section{LEI DOS COSSENOS}

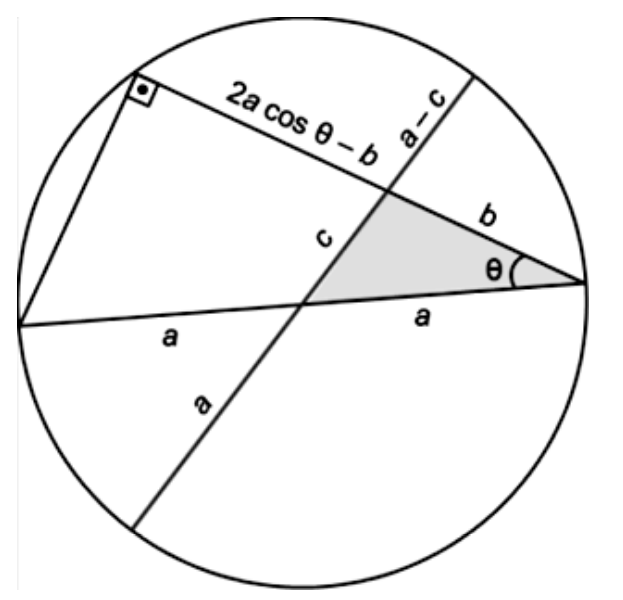

Utilizando a potência de ponto, temos

$(2 a \cos \theta-b) b=(a-c)(a+c)$

$c^{2}=a^{2}+b^{2}-2 a b \cos \theta$

Figura 2. Triângulo inscrito na circunferência. 


\section{LEI DOS SENOS}

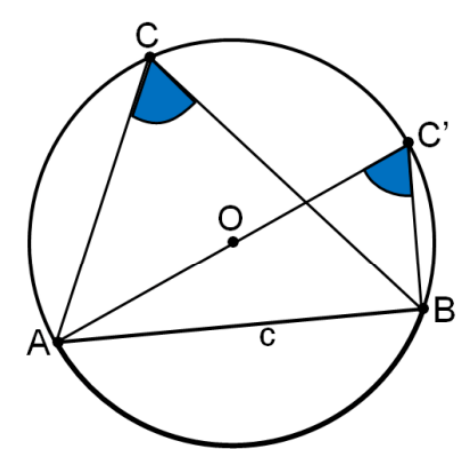

Figura 4. Triângulo $\triangle A B C$ e triângulo retângulo $\triangle A B C^{\prime}$.

$$
\begin{gathered}
\operatorname{sen} C^{\prime}=\frac{c}{2 R}, \operatorname{como} C \equiv C^{\prime} \\
2 R=\frac{C}{\operatorname{sen} C}
\end{gathered}
$$

Analogamente,

$$
2 R=\frac{c}{\operatorname{sen} C}=\frac{a}{\operatorname{sen} A}=\frac{b}{\operatorname{sen} B}
$$

\section{LEI DAS TANGENTES}

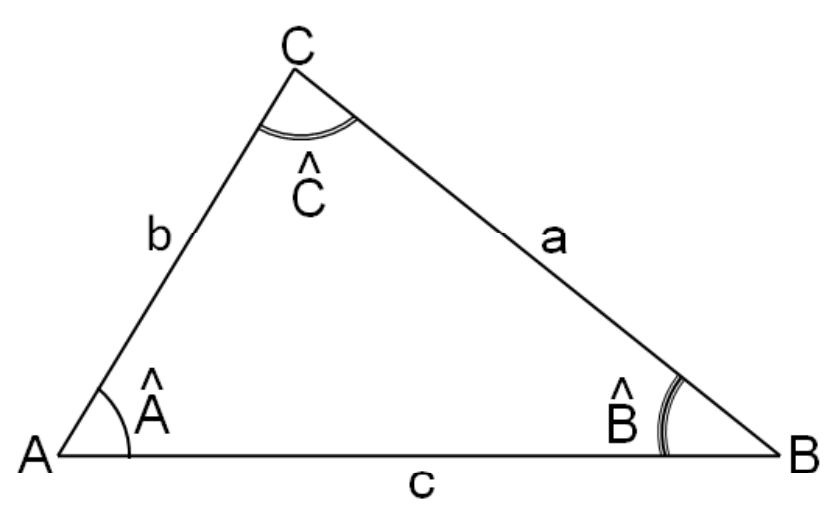

Figura 5. Triângulo $\triangle A B C$, com ângulos internos.
Usando a lei dos senos,

$$
\frac{a+b}{\operatorname{sen} \hat{\mathrm{A}}+\operatorname{sen} \hat{B}}=\frac{a-b}{\operatorname{sen} \hat{\mathrm{A}}-\operatorname{sen} \hat{B}}
$$

Pelas Relações de Prostaférese, obtemos,

$$
\frac{a-b}{a+b}=\frac{\operatorname{tg}\left(\frac{\widehat{A}-\widehat{B}}{2}\right)}{\operatorname{tg}\left(\frac{\widehat{A}+\widehat{B}}{2}\right)}
$$

\section{TEOREMA DE STEWART}

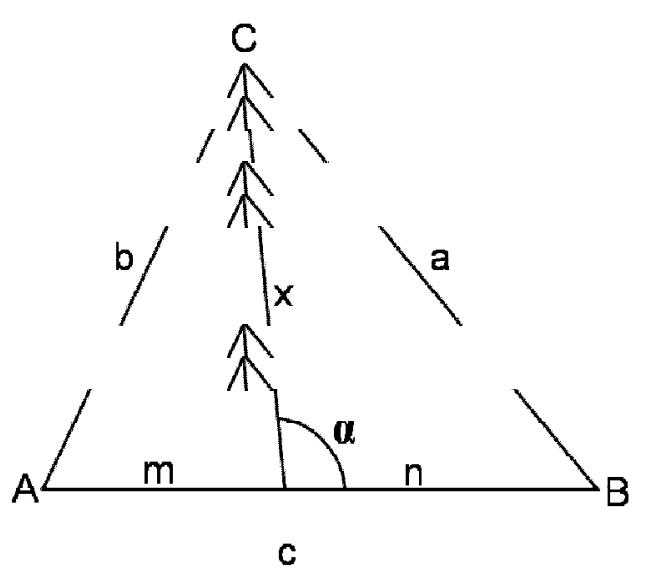

Figura 6. Triângulo $\triangle A B C$ com ceviana.
Utilizando a lei dos cossenos:

$$
\begin{aligned}
& b^{2}=m^{2}+x^{2}+2 m x \cdot \cos \alpha(I) \\
& a^{2}=n^{2}+x^{2}-2 m x \cdot \cos \alpha(I I)
\end{aligned}
$$

multiplicando (I) por $\mathrm{n}$, (II) por $\mathrm{m}$ e somando obtém-se,

$$
b^{2} n+a^{2} m-x^{2} c=m n c
$$




\section{ÁREAS DE TRIÂNGULOS}

$1^{\circ}$ caso - Circunferência de raio r inscrita no triângulo $\triangle A B C$

Construindo os triângulos, $\triangle A O B, \triangle B O C$ e $\triangle C O A$, suas respectivas áreas são:

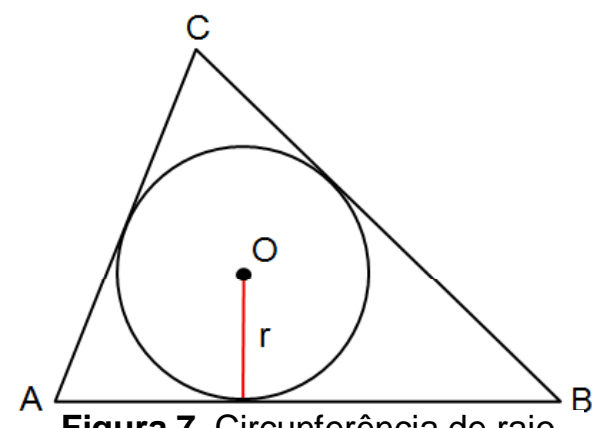

$$
\frac{c . r}{2} ; \frac{a . r}{2} e \frac{b \cdot r}{2}
$$

assim,

$$
(\mathrm{ABC})=\mathrm{p} \cdot \mathrm{r}
$$

Figura 7. Circunferência de raio

$r$, inscrita no triângulo.

$2^{\circ}$ caso - Circunferência de raio $R$ circunscrita ao triângulo $\triangle \mathrm{ABC}$.

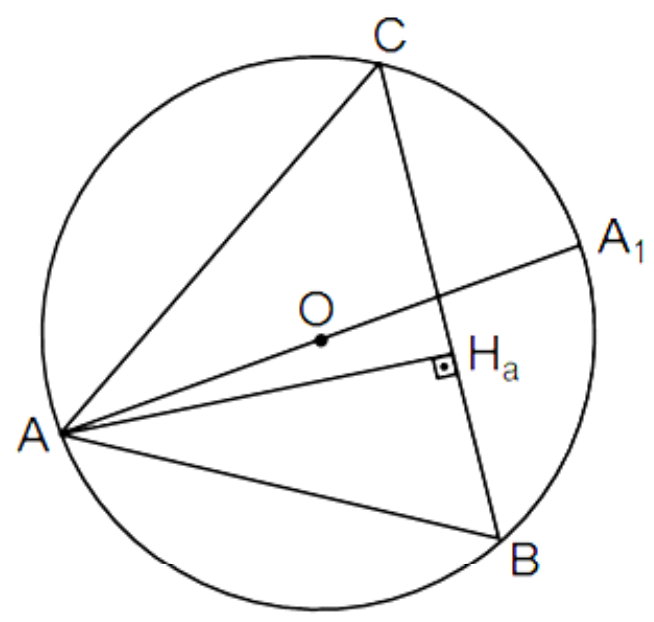

$$
\begin{gathered}
\triangle A B H_{a} \sim \triangle A A_{1} C, \text { caso }(A A), \text { então } \\
\frac{A B}{A A_{1}}=\frac{A H_{a}}{A C} \\
A H_{a}=h_{a}=\frac{A C \cdot A B}{A A_{1}}=\frac{B C}{2 R} \\
(A B C)=\frac{1}{2} a h_{a}=\frac{a b c}{4 R}
\end{gathered}
$$

Figura 8. Triângulo $\triangle A B C$ inscrito na circunferência de diâmetro $A A_{1}$

3ํo caso - Dois lados e o ângulo interno entre eles.

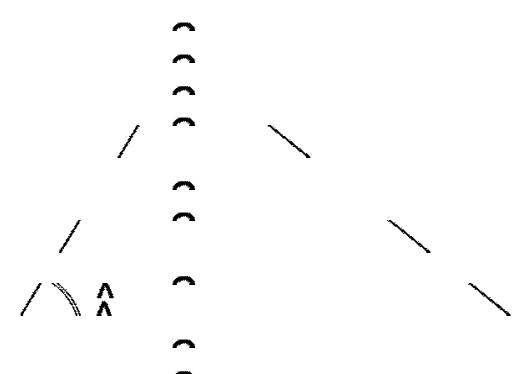

A altura do $\triangle \mathrm{ABC}$ em relação ao lado $\overline{A B}$ é:

Figura $\hat{9}$. Triấngulo $\triangle A B C$

$$
\begin{gathered}
b \operatorname{sen} \hat{A}, \quad \text { assim, } \\
(A B C)=\frac{1}{2} c b \operatorname{sen} \hat{A}
\end{gathered}
$$


$4^{\circ}$ caso - Em função dos três ângulos internos e um lado do triângulo.

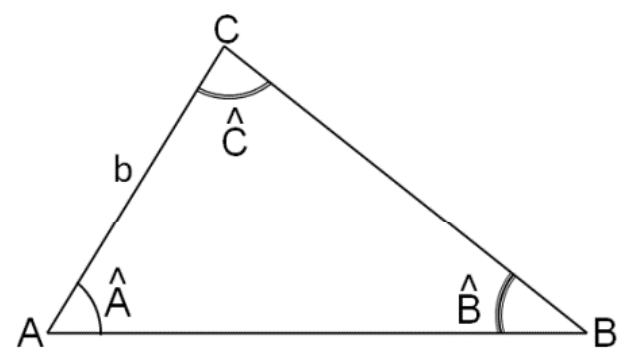

Pela lei dos senos, temos

$$
\frac{b}{\operatorname{sen} \widehat{B}}=\frac{c}{\operatorname{sen} \hat{C}}
$$

Figura 10. Triângulo $\triangle A B C$, com destaque nos ângulos internos

assim:

$$
(A B C)=\frac{b^{2}(\operatorname{sen} \hat{A} \cdot \operatorname{sen} \hat{C})}{2 \cdot \operatorname{sen} \widehat{B}}
$$

5 caso - Em função dos lados - FÓRMULA DE HERON

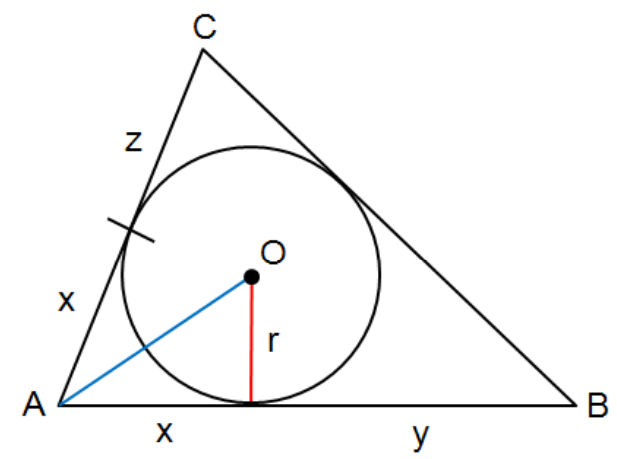

Figura 11. Circunferência inscrita ao triângulo $\triangle A B C$.

$$
(A B C)=\sqrt{p(p-a)(p-b)(p-c)}
$$

\section{Prova:}

$$
\operatorname{sen}\left(\frac{A}{2}\right)=\frac{r}{\sqrt{r^{2}+x^{2}}} e \cos \left(\frac{A}{2}\right)=\frac{x}{\sqrt{r^{2}+x^{2}}}
$$

$$
\begin{gathered}
h_{c}=b \operatorname{sen} \hat{A}=2 b \operatorname{sen}\left(\frac{A}{2}\right) \cdot \cos \left(\frac{A}{2}\right)=\frac{2 r x}{r^{2}+x^{2}} \cdot b=\frac{2(x+z)}{r^{2}+x^{2}} \cdot r x \\
(A B C)=r p=\frac{1}{2}(x+y)(x+z) \cdot\left(\frac{2 r x}{r^{2}+x^{2}}\right) \\
p\left(r^{2}+x^{2}\right)=x(x+y)(x-z)=x[x(x+y+z)+y z]=x(x s+y z) \\
p r^{2}+o x^{2}=p x^{2}+x y z \\
p r^{2}=x y z \\
(A B C)=p r=\sqrt{p\left(p r^{2}\right)}=\sqrt{p(x y z)}=\sqrt{p(p-a)(p-b)(p-c)}
\end{gathered}
$$




\section{TEOREMA DE PTOLOMEU}

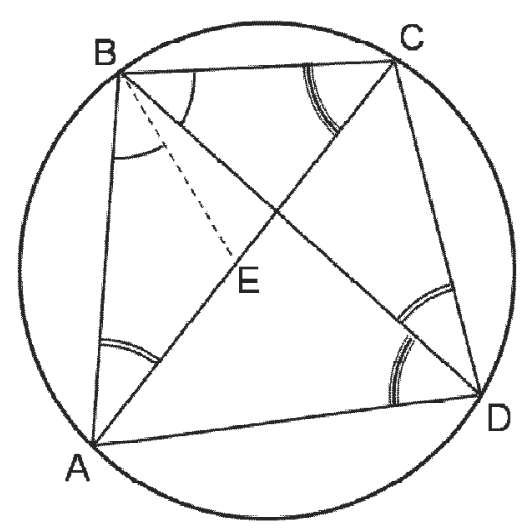

Quadrilátero ABCD inscrito na circunferência.

Sobre a diagonal $A C$ marca-se um ponto $E$, de tal forma que $A \widehat{B} E=C \widehat{B} D$.

O teorema é:

$$
B D \cdot A C=A B \cdot C D+A D \cdot B C
$$

Figura 12. Circunferência circunscrita ao quadrilátero $A B C D$.

Prova:

$$
\begin{aligned}
& \triangle A B E \sim \triangle D B C \Rightarrow A E \cdot B D=A B \cdot C D(I) \\
& \triangle B C E \sim \triangle B D A \Rightarrow C E \cdot B D=A D \cdot B C(I I)
\end{aligned}
$$

Somando I e II obtemos:

$$
B D(A E+C E)=A B \cdot C D+A D \cdot B C
$$

como $A E+C E=A C$, chega-se a:

$$
B D \cdot A C=A B \cdot C D+A D \cdot B C
$$

Uma outra maneira de demonstrar da Lei dos Cossenos, é utilizando o Teorema de Ptolomeu:

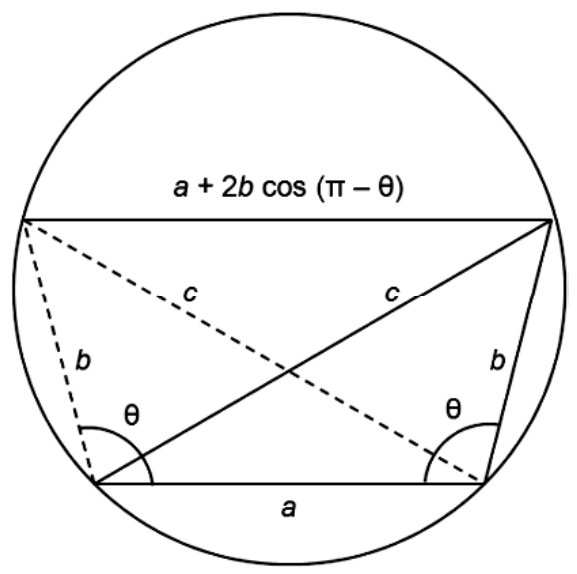

$$
\begin{gathered}
c \cdot c=b \cdot b+(a+2 b \cos (\pi-\theta)) \cdot a \\
c^{2}=a^{2}+b^{2}-2 a b \cos \theta
\end{gathered}
$$

Figura 13. Trapézio isósceles inscrito na circunferência 


\section{EQUAÇÃO DE MOLLWEIDE}

As duas equações abaixo relacionam os três lados e os três ângulos internos de um triângulo qualquer, sendo conhecidas como Equações de Mollweide.

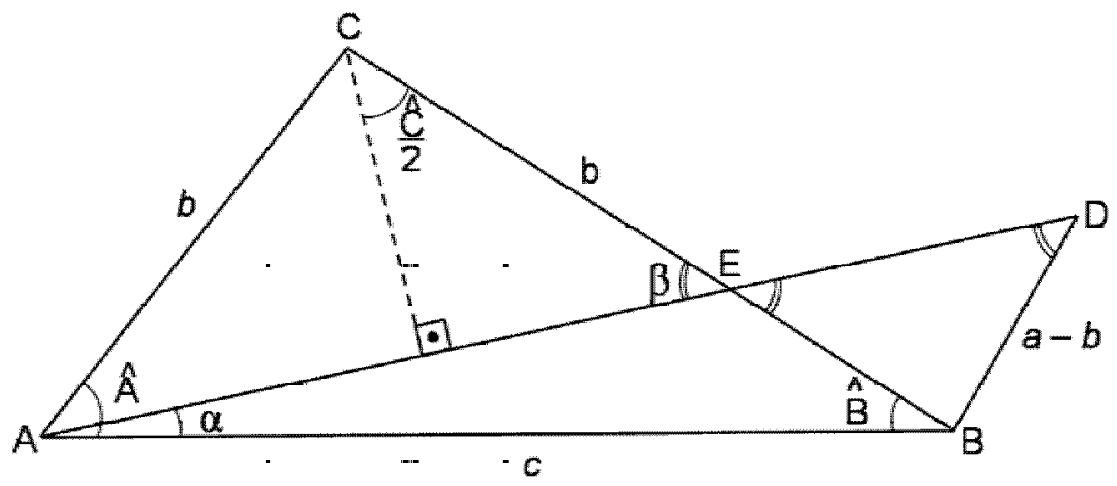

Figura 14. O triângulos $\triangle A B C$ é o triângulo de "partida" para a demonstração.

A partir do $\triangle A B C$ construímos um triângulo isósceles $\triangle A C E$ de base $A E$. Pelo vértice $A$, construímos o segmento $A D$, passando por $E$, e BD igual a $B E$, assim:

$$
\beta=\frac{\hat{A}+\hat{B}}{2} \text { e } \alpha=\frac{\hat{A}-\hat{B}}{2}
$$

Aplicando a Lei dos senos no triângulo $\triangle A B D$, chega-se:

$$
\begin{aligned}
& (a-b) \cdot \cos \left(\frac{\hat{C}}{2}\right)=c \cdot \operatorname{sen}\left(\frac{\hat{A}-\hat{B}}{2}\right) \\
& (a+b) \cdot \operatorname{sen}\left(\frac{\hat{C}}{2}\right)=c \cdot \cos \left(\frac{\hat{A}-\hat{B}}{2}\right)
\end{aligned}
$$




\section{TEOREMA DE CEVA}

Para que três cevianas quaisquer sejam concorrentes a um ponto $P$ é necessário e suficiente que,

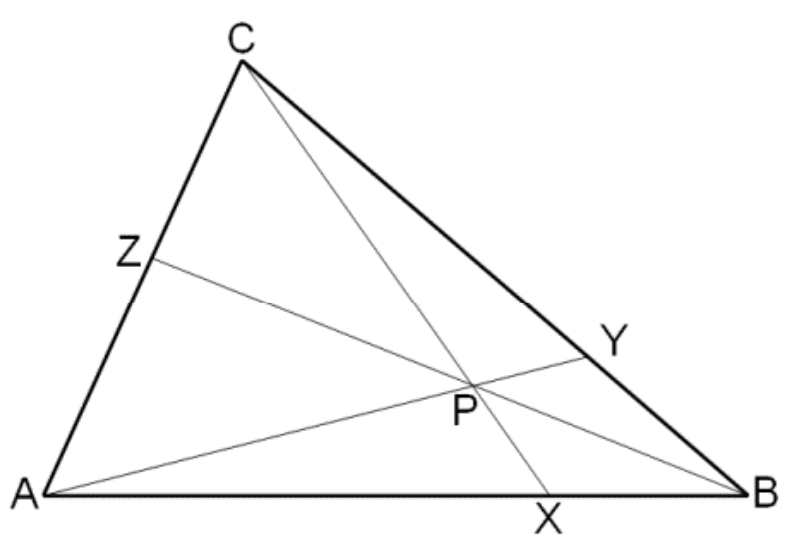

$$
\frac{B Y}{Y C} \cdot \frac{B X}{X A} \cdot \frac{C Z}{Z A}=1
$$

A demonstração é facilmente verificada usando razões entre as áreas dos triângulos adotando o ponto $\mathrm{P}$ como um dos vértices do triângulo. Exemplo:

Figura 15. Ponto $P$, encontro das cevianas.

$$
\frac{B Y}{Y C}=\frac{\triangle B P Y}{\Delta C P Y}=\frac{\triangle B A Y-\triangle B P Y}{\triangle C A Y-\triangle C P Y}=\frac{\triangle A P X}{\triangle A C P}
$$

De modo análogo as outras razões são encontradas, e chega-se a,

$$
\frac{B Y}{Y C} \cdot \frac{B X}{X A} \cdot \frac{C Z}{Z A}=1
$$

\section{TEOREMA DE MENELAU}

Se $N, M$ e $L$ são pontos das retas suportes dos lados do triângulo $\triangle A B C$ e esses pontos são colineares, então é válida a igualdade:

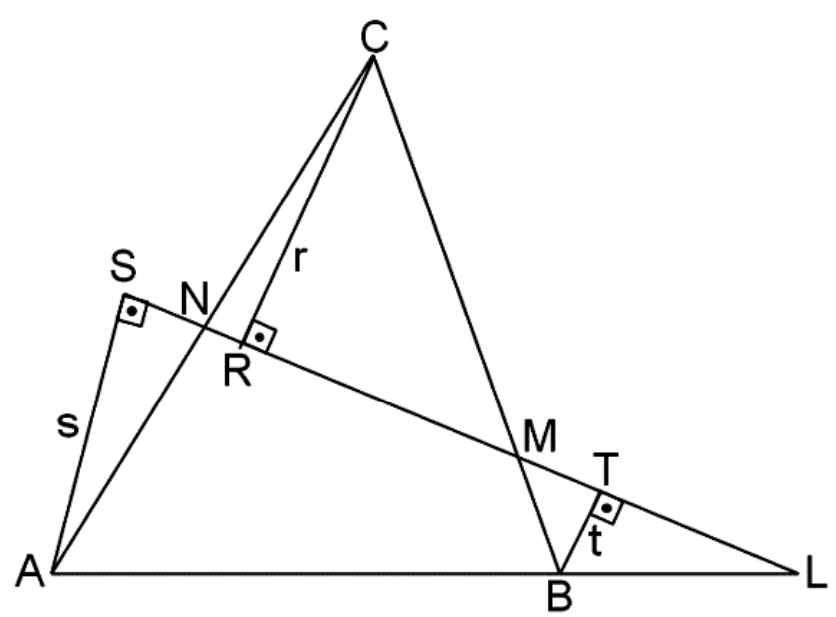

$$
\frac{A L}{B L} \cdot \frac{B M}{M C} \cdot \frac{C N}{A N}=1
$$

Figura 16. Pontos $\mathrm{N}, \mathrm{M}$ e L são colineares, Pertencem às retas suporte dos lados do triângulo $\triangle A B C$ 
Prova: Os pontos $S, R$ e $T$ são colineares e pertencem á reta que contém os pontos $\mathrm{N}, \mathrm{M}$ e L. Esses pontos foram determinados pela intersecção da reta perpendicular à reta que contém os pontos $M, N$ e $L$ e que passa pelos vértices do triângulo $\triangle A B C$. Usando semelhança de triângulos obtemos:

$$
\begin{gathered}
\triangle C R N \sim \triangle A S N \Rightarrow \frac{r}{s}=\frac{C N}{A N} \\
\triangle A S L \sim \triangle B T L \Rightarrow \frac{s}{t}=\frac{A L}{B L} \\
\triangle B T M \sim \triangle C R M \Rightarrow \frac{t}{r}=\frac{B M}{C M}
\end{gathered}
$$

Multiplicando I, II e III, obtemos:

$$
\begin{gathered}
\frac{r}{s} \cdot \frac{s}{t} \cdot \frac{t}{r}=\frac{C N}{A N} \cdot \frac{A L}{B L} \cdot \frac{B M}{C M} \\
\frac{C N}{A N} \cdot \frac{A L}{B L} \cdot \frac{B M}{C M}=1
\end{gathered}
$$

\section{TEOREMA DA BISSETRIZ INTERNA}

- pelo vértice $B$ do triângulo traça-se

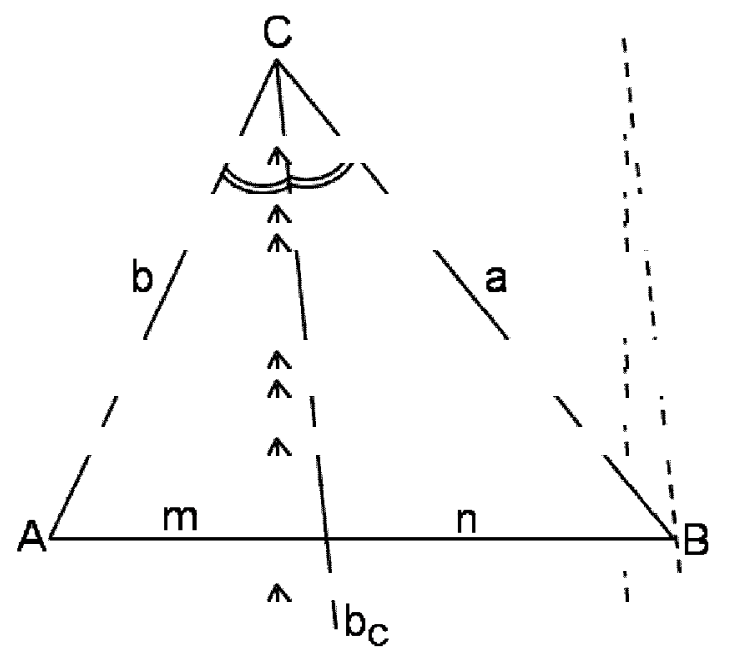

Figura 17. Bissetriz interna de um triângulo uma reta paralela a $b_{c}$;

- constrói-se um triângulo isósceles de lados a, utilizando os vértices $B, C$ e a reta paralela construída anteriormente;

- por fim, utilizando as relações de ângulo de retas paralelas cortadas por uma transversal aplicamos o Teorema de Tales,

$$
\frac{m}{b}=\frac{n}{a}
$$




\section{TEOREMA DA BISSETRIZ EXTERNA}

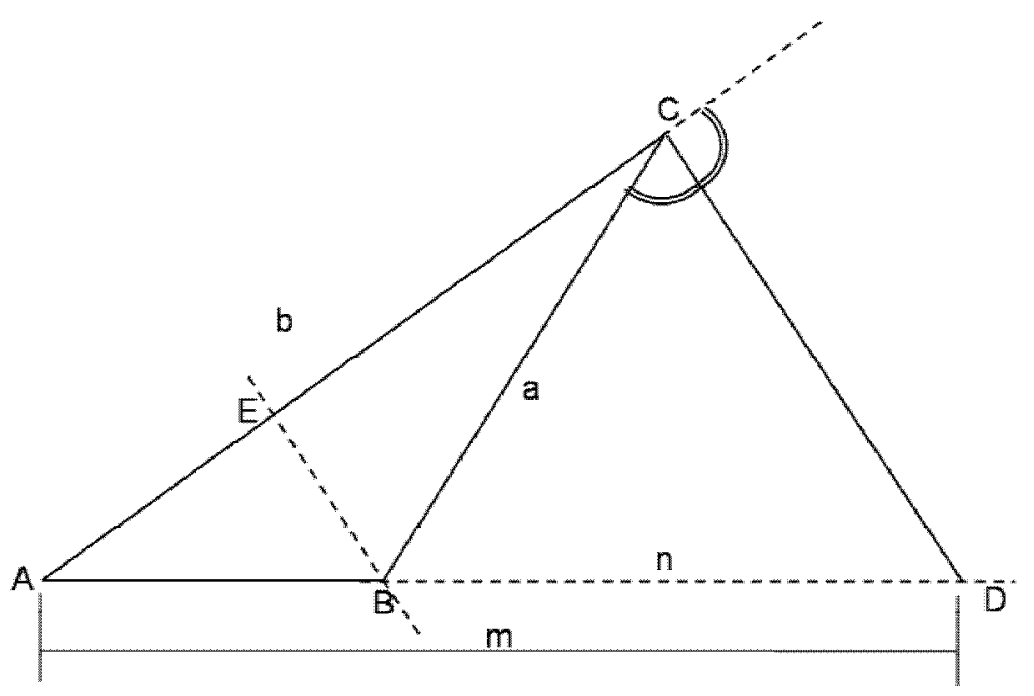

Figura 18. $C D$ é a bissetriz externa do triângulo $\triangle A B C$

- a partir do $\triangle \mathrm{ABC}$, determina-se a bissetriz externo do ângulo $\hat{C}$;

- passando por B constrói-se uma paralela a CD;

-por fim, usando as relações angulares das retas paralelas cortadas por uma transversal obtemos que $\triangle B E C$ é isósceles e pelo teorema de Tales, obtemos:

$$
\frac{m}{b}=\frac{n}{a}
$$




\section{CAPÍTULO 2}

\section{Os Pontos Notáveis de um Triângulo}

O objetivo deste capítulo é o de mostrar que os pontos notáveis de um triângulo têm a propriedade de serem pontos de máximo e mínimo de uma dada função entre todos os pontos interiores de uma região triangular. As funções apresentadas nesse capítulo foram retiradas da referência [12].

Para estas demonstrações de máximos e mínimos, não serão utilizadas as ferramentas do cálculo e sim a desigualdade de Cauchy-Schwarz, que diz:

$$
\left(\sum_{k=1}^{n} x_{k} y_{k}\right)^{2} \leq\left(\sum_{k=1}^{n} x_{k}^{2}\right)\left(\sum_{k=1}^{n} y_{k}^{2}\right)
$$

Essa desigualdade é válida para qualquer $\mathrm{x}$ e y com $\mathrm{n}$ elementos.

Demonstração:

Qualquer que seja o real $\lambda$, toma-se $(x-\lambda y)$ e tem:

$$
\sum_{k=1}^{n}\left(x_{k}-\lambda y_{k}\right)^{2}=\sum_{k=1}^{n}\left(x_{k}\right)^{2}-2 \lambda \sum_{k=1}^{n} x_{k} y_{k}+\lambda^{2} \sum_{k=1}^{n}\left(y_{k}\right)^{2}
$$

Independente do valo de $\lambda$, o valor sempre será positivo ou igual a zero quando, pois

$$
\sum_{k=1}^{n}\left(x_{k}-\lambda y_{k}\right)^{2}
$$

é não negativo

$$
\sum_{k=1}^{n}\left(x_{k}\right)^{2}-2 \lambda \sum_{k=1}^{n} x_{k} y_{k}+\lambda^{2} \sum_{k=1}^{n}\left(y_{k}\right)^{2} \geq 0
$$

Isso implica que o discriminante seja negativo ou nulo

$$
\Delta=\left(2 \sum_{k=1}^{n} x_{k} y_{k}\right)^{2}-4\left(\sum_{k=1}^{n}\left(y_{k}\right)^{2}\right)\left(\sum_{k=1}^{n}\left(x_{k}\right)^{2}\right) \leq 0
$$


Significando que

$$
\left(\sum_{k=1}^{n} x_{k} y_{k}\right)^{2} \leq\left(\sum_{k=1}^{n} x_{k}^{2}\right)\left(\sum_{k=1}^{n} y_{k}^{2}\right)
$$

\subsection{Caracterização do Incentro (I) do Triângulo ABC como Ponto de Máximo}

O incentro (I) do triângulo $A B C$ é definido como o ponto de intersecção das três bissetrizes internas.

O incentro (I) tem a propriedade de ser o ponto cuja soma das três raízes quadradas das três distâncias às arestas de um triângulo equilátero é a máxima da função

$$
f(x, y, z)=\sqrt{x}+\sqrt{y}+\sqrt{z}
$$

em que $x, y$ e $z$ são as distâncias de um ponto interno $P$ do triângulo equilátero aos seus lados, pois:

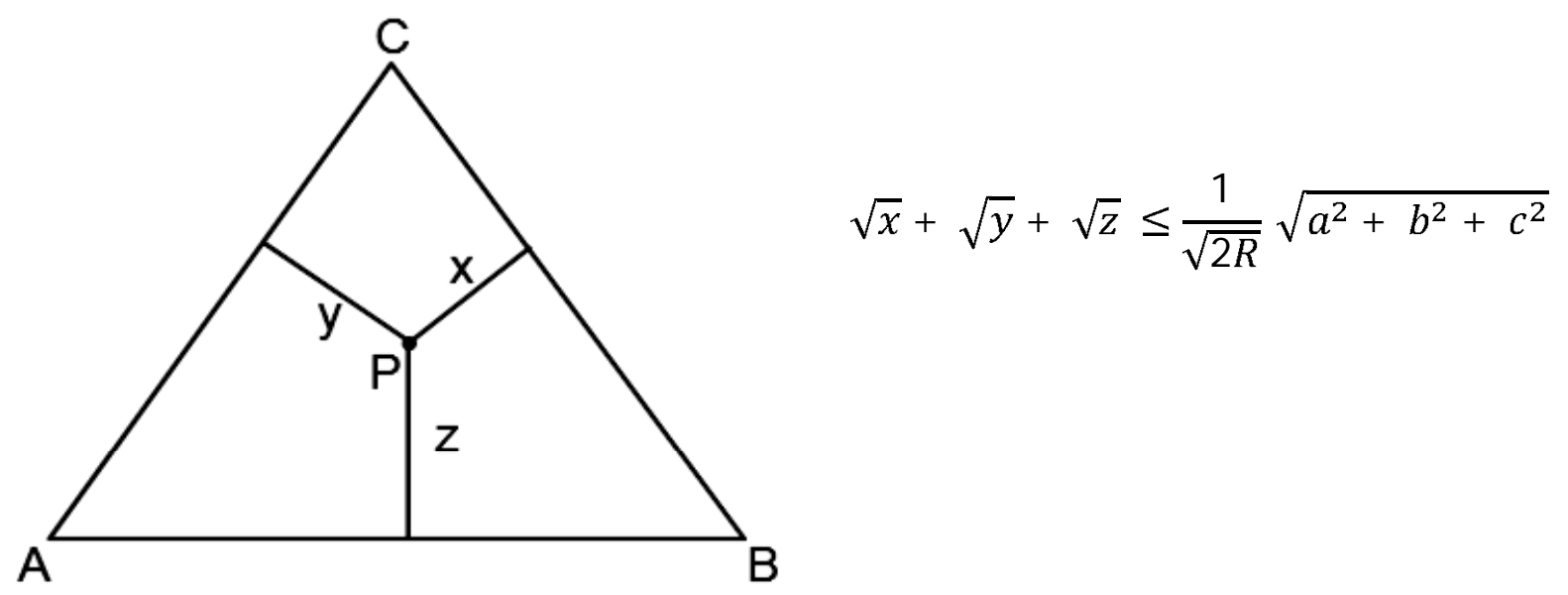

Figura 19. Distâncias do ponto $\mathrm{P}$ aos lados do triângulo equilátero.

E a validade da igualdade nessa desigualdade acontece no caso de triângulos equiláteros e no caso de $P$ ser o incentro do triângulo.

De fato, pela Desigualdade de Cauchy - Schwarz: 


$$
\sqrt{x}+\sqrt{y}+\sqrt{z}=\sqrt{a x} \sqrt{\frac{1}{a}}+\sqrt{b y} \sqrt{\frac{1}{b}}+\sqrt{c z} \sqrt{\frac{1}{c}} \leq \sqrt{a x+b y+c z} \sqrt{\frac{1}{a}+\frac{1}{b}+\frac{1}{c}}
$$

e a validade da igualdade nesta desigualdade acontece quando,

$$
\begin{gathered}
\sqrt{a x}=\sqrt{b y}=\sqrt{c z} \\
a x+b y+c z=2(A B C)=\frac{a b c}{2 R} \\
\sqrt{x}+\sqrt{y}+\sqrt{z} \leq \sqrt{\frac{a b c}{2 R}} \sqrt{\frac{1}{a}+\frac{1}{b}+\frac{1}{c}}=\frac{1}{\sqrt{2 R}} \sqrt{a b+a c+b c} \\
a b+a c+b c \leq \sqrt{a^{2}+b^{2}+c^{2}} \sqrt{a^{2}+b^{2}+c^{2}}
\end{gathered}
$$

com igualdade válida no caso $\frac{b}{c}=\frac{c}{a}=\frac{a}{b}$ ou $a=b=c$.

Portanto,

$$
\sqrt{x}+\sqrt{y}+\sqrt{z} \leq \frac{1}{\sqrt{2 R}} \sqrt{a^{2}+b^{2}+c^{2}}
$$

e a igualdade é válida quando e somente quando $a=b=c$ ou $a^{2} x=b^{2} y=c^{2} z$ ou $x=y=z$

O valor máximo da função $f(x, y, z)$ ocorre no incentro $(I)$ do triângulo equilátero e é igual a $\frac{\sqrt{3 a^{2}}}{\sqrt{2 R}}$. 


\subsection{Caracterização do Incentro (I) do Triângulo ABC como ponto de mínimo}

Utilizando um triângulo qualquer, o incentro (I) tem a propriedade de ser 0 ponto cuja raiz da soma do quociente entre o lado e a sua respectiva distância ao ponto P é a mínima da função

$$
g(x, y, z)=\sqrt{\frac{a}{x}+\frac{b}{y}+\frac{c}{z}}
$$

em que $x, y$ e z são as distâncias de um ponto $P$ interno do triângulo aos seus três lados,

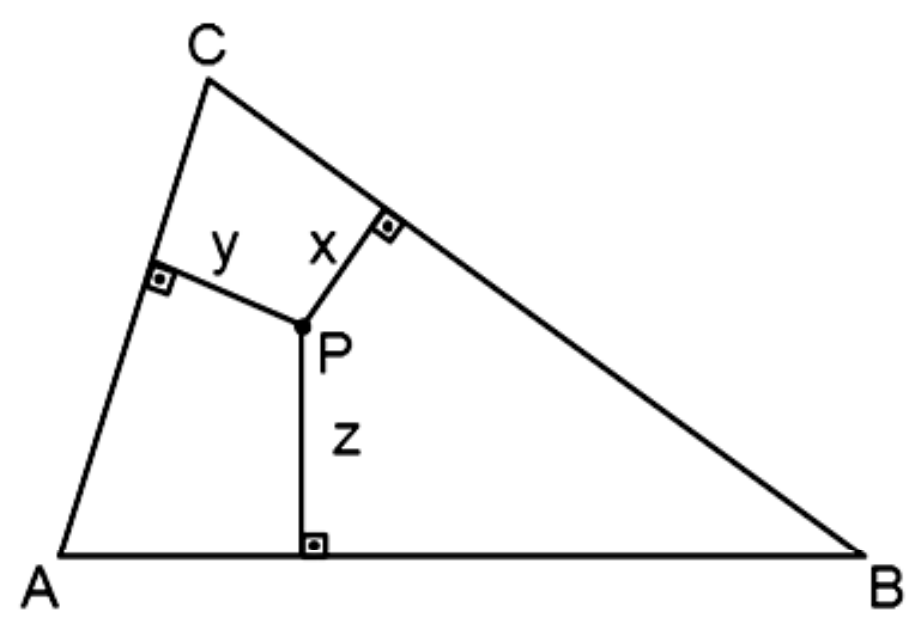

Figura 20. Distâncias do ponto $P$ aos lados do triângulo.

pois a validade da igualdade na desigualdade de Cauchy-Schwarz,

$$
\begin{gathered}
a+b+c=\sqrt{a x} \sqrt{\frac{a}{x}+\sqrt{b y} \sqrt{\frac{b}{y}}+\sqrt{c z} \sqrt{\frac{c}{z}} \leq \sqrt{a x+b y+c z} \sqrt{\frac{a}{x}+\frac{b}{y}+\frac{c}{z}}} \\
\sqrt{a x+b y+c z} \sqrt{\frac{a}{x}+\frac{b}{y}+\frac{c}{z}} \leq \sqrt{2(A B C)} \sqrt{\frac{a}{x}+\frac{b}{y}+\frac{c}{z}}
\end{gathered}
$$

acontece quando e somente quando,

$$
\frac{\sqrt{a x}}{\sqrt{\frac{a}{x}}}=\frac{\sqrt{b y}}{\sqrt{\frac{b}{y}}}=\frac{\sqrt{c z}}{\sqrt{\frac{c}{z}}} \quad \text { ou } \quad x=y=z
$$


O valor mínimo da função $g(x, y, z)$

$$
\sqrt{\frac{a}{x}+\frac{b}{y}+\frac{c}{z}}
$$

ocorre no incentro $(I)$ do triângulo e é igual a:

$$
\frac{a+b+c}{\sqrt{2(A B C)}}
$$

\subsection{Caracterização do Centróide (G) do Triângulo ABC como Ponto de Máximo}

O centróide $(G)$ do triângulo $\triangle A B C$, é definido como o ponto de intersecção das três medianas do triângulo.

A mediana $\left(m_{a}\right)$ é o segmento de reta cujos extremos são o vértice $A$ e o ponto médio $M_{a}$ do lado.

O centróide $(\mathrm{G})$ tem a propriedade de ser o ponto de máximo do produto das três distâncias de um ponto interno às arestas do triângulo da função simétrica

$$
f(x, y, z)=x y z
$$

em que $x, y$ e $z$ indicam distâncias de um ponto interno do triângulo aos lados $B C$, $A C$ e $A B$ do triângulo respectivamente, isto é, entre todos os pontos internos do triângulo, o centróide tem a propriedade de maximizar o produto de suas três distâncias aos lados do triângulo. 
De fato,

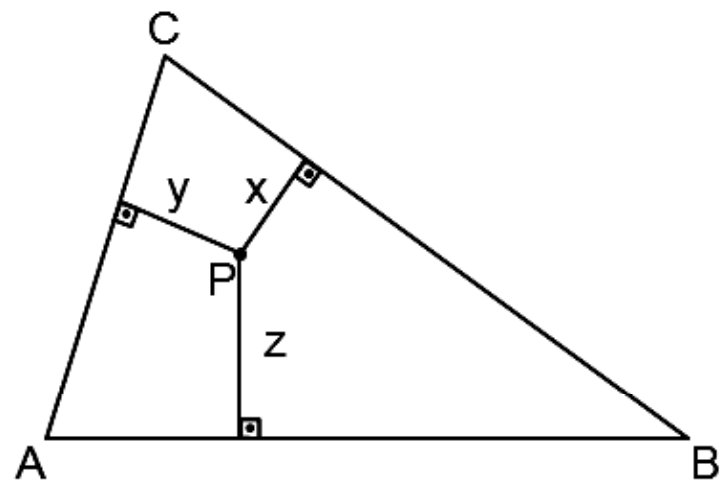

Figura 21 - Ponto $P$ interno ao triângulo

a desigualdade entre médias aritmética e geométrica nos diz que

$$
\sqrt[3]{(a x)(b y)(c z)} \leq \frac{a x+b y+c z}{3}=\frac{2(A B C)}{3}
$$

ou

$$
x y z \leq \frac{8(A B C)^{3}}{27 a b c}
$$

A igualdade ocorre quando e somente quando

$$
a x=b y=c z
$$

ou equivalentemente que o ponto de máximo de $f(x, y, z)$ é o centróide $(\mathrm{G})$ do triângulo e o valor máximo é $\frac{8(A B C)^{3}}{27 a b c}$, de fato,

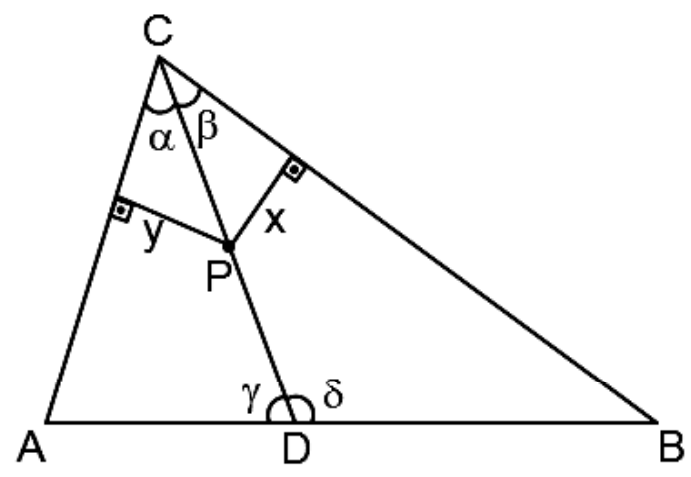

$$
\begin{aligned}
& \frac{\operatorname{sen} \gamma}{b}=\frac{\operatorname{sen} \beta}{A D}=\frac{\operatorname{sen} A}{C D} \\
& \frac{\operatorname{sen} \delta}{a}=\frac{\operatorname{sen} \alpha}{B D}=\frac{\operatorname{sen} B}{C D} \\
& b \operatorname{sen} \beta=A D \operatorname{sen} \gamma \\
& a \operatorname{sen} \alpha=B D \operatorname{sen} \delta
\end{aligned}
$$

Figura 22 - Relação entre os ângulos da mediana de um triângulo e o ponto $P$.

$$
\frac{A D}{B D}=\frac{b \operatorname{sen} \beta}{a \operatorname{sen} \alpha}=\frac{b y / C P}{a x / C P}=\frac{b y}{a x}
$$




$$
\frac{A D}{B D}=1=\frac{b y}{a x}
$$

como $A D=B D, D$ pertence à mediana $m_{a}$ do triângulo e analogamente pertence as outras duas medianas e, portanto, é a intersecção das três medianas.

Assim, o centróide $(G)$ do triângulo $\triangle A B C$ tem a propriedade de que as suas distâncias $x_{G}, y_{G}$ e $z_{G}$ aos lados do triângulo são inversamente proporcionais às medidas $a, b$ e $c$ dos lados:

$$
a x_{G}=b y_{G}=c z_{G}
$$




\section{CAPÍTULO 3}

3 Coordenadas Cartesianas dos Pontos Notáveis de um Triangulo

Nesse capítulo, determinaremos as coordenadas dos pontos notáveis com o triângulo em posição especial, ou seja, um dos vértices se encontra na origem do plano cartesiano e um dos lados está contido no eixo das abscissas e o outro vértice possui coordenadas positivas. Para a determinação das coordenadas dos pontos notáveis do triângulo em qualquer posição será necessário fazer a translação das coordenadas, de modo que esse caso não será abordado no presente trabalho.

Consideraremos um sistema cartesiano de coordenadas cuja origem é um dos vértices do triângulo (no caso da figura o vértice $A$ ), cujo eixo das abscissas é a reta suporte de um dos lados do triângulo (no caso da figura o lado $A B$ ), de modo que o vértice $B$ tenha abscissa positiva e de modo que o vértice $C$ tenha ordenada positiva:

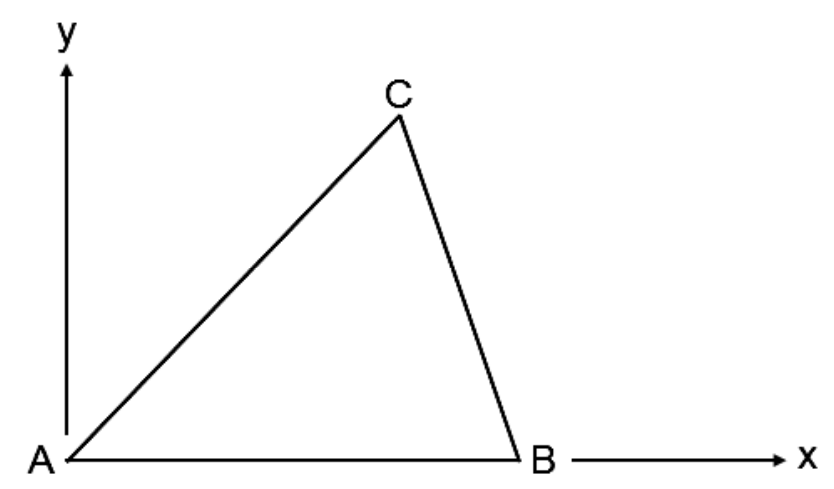

Figura 23 - Posição especial do triângulo no plano cartesiano. 


\section{AS COORDENADAS CARTESIANAS DO ORTOCENTRO (H)}

$\mathrm{O}$ ortocentro $(H)$ é definido como ponto de intersecção das três alturas do triângulo.

$$
x_{H}=\frac{b^{2}+c^{2}-a^{2}}{2 c} \quad e \quad y_{H}=\frac{2(A B C)}{c}+\frac{c\left(c^{2}-a^{2}-b^{2}\right)}{4(A B C)}
$$

Prova: Cálculo das coordenadas cartesianas do ortocentro $(O)$.

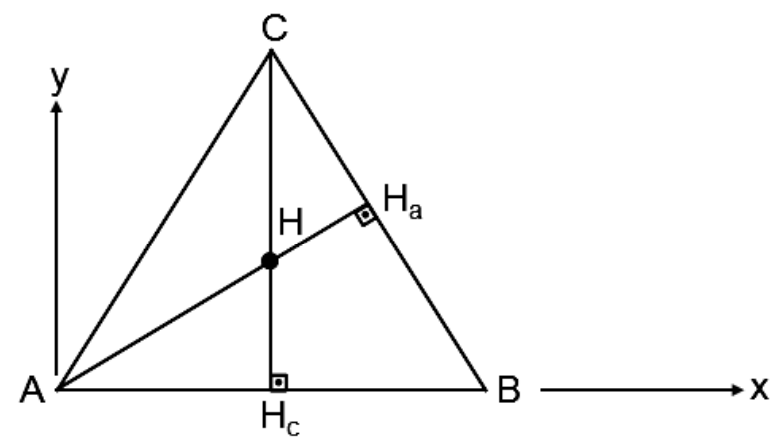

Figura 24. Ponto $\mathrm{H}$ encontro das alturas

Pela lei dos cossenos:

$$
\begin{array}{ccc}
a^{2}=b^{2}+c^{2}-2 b c \cos \hat{A}=b^{2}+c^{2}-2 b c\left(\frac{A H_{c}}{b}\right) & \rightarrow & A H_{c}=\frac{b^{2}+c^{2}-a^{2}}{2 c} \\
b^{2}=a^{2}+c^{2}-2 a c \cos \hat{B}=a^{2}+c^{2}-2 a c\left(\frac{A H_{a}}{c}\right) & \rightarrow & A H_{a}=\frac{a^{2}+c^{2}-b}{2 a} \\
(A B C)=\frac{1}{2} B C \cdot A H_{a} \quad & \rightarrow
\end{array}
$$

Em relação aos triângulos semelhantes $-\triangle A B H_{a} \sim \triangle A H H_{c}$

$$
\frac{B H_{a}}{A H_{a}}=\frac{H H_{c}}{A H_{c}}
$$




$$
\begin{gathered}
H H_{c}=\frac{A H_{c} \cdot B H_{a}}{A H_{a}} \\
H H_{c}=\frac{b^{2}+c^{2}-a^{2}}{2 c} \cdot \frac{a^{2}+c^{2}-b}{2 a} \cdot \frac{a}{2(A B C)} \\
H H_{c}=\frac{a^{2} b^{2}+b^{2} c^{2}-b^{4}+a^{2} c^{2}+c^{4}-b^{2} c^{2}-a^{4}-a^{2} c^{2}+a^{2} b^{2}}{8 c(A B C)} \\
H H_{c}=\frac{2 a^{2} b^{2}-a^{4}-b^{4}+c^{4}}{8 c(A B C)}=\frac{16(A B C)^{2}-2 a^{2} c^{2}-2 b^{2} c^{2}+2 c^{4}}{8 c(A B C)} \\
H H_{c}=\frac{2(A B C)}{c}+\frac{c\left(c^{2}-a^{2}-b^{2}\right)}{4(A B C)}
\end{gathered}
$$

Portanto, as coordenadas do ORTOCENTRO $(H)$ são

$$
\begin{gathered}
x_{H}=\frac{b^{2}+c^{2}-a^{2}}{2 c} \\
y_{H}=\frac{2(A B C)}{c}+\frac{c\left(c^{2}-a^{2}-b^{2}\right)}{4(A B C)}
\end{gathered}
$$

Como mostrado no capítulo 1, é possível com a fórmula de Heron calcular a área de um triângulo apenas com as medidas dos lados. Abaixo, mostramos uma outra maneira de calcular a área do triângulo em função de seus lados:

$$
\begin{aligned}
16(A B C)^{2} & =\{[(b+c)+a] \cdot[(b+c)-a] \cdot[a-(b-c)] \cdot[a+(b-c)]\} \\
& =\left[(b+c)^{2}-a^{2}\right] \cdot\left[a^{2}-(b-c)^{2}\right] \\
& =2 a^{2} b^{2}+2 a^{2} c^{2}+2 b^{2} c^{2}-a^{4}-b^{4}-c^{4}
\end{aligned}
$$

\section{AS COORDENADAS CARTESIANAS DO CENTRÓIDE (G)}

$$
x_{G}=\frac{3 c^{2}+b^{2}-a^{2}}{6 c} \quad e \quad y_{G}=\frac{2}{3} \frac{(A B C)}{c}
$$


Prova: Cálculo das coordenadas cartesianas do Centróide $(G)$

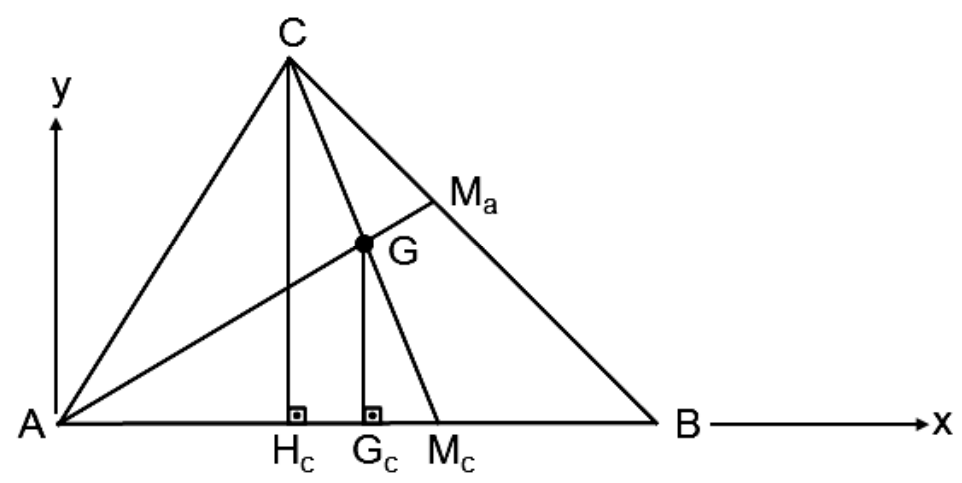

Figura 25. Ponto $G$, encontro das medianas

$$
(A B C)=\frac{1}{2} A B \cdot C H_{c} \quad e \quad C H_{C}=\frac{2(A B C)}{c}
$$

Em relação aos triângulos semelhantes $-\Delta M_{c} G_{C} G \sim \Delta M_{c} H_{c} C$

$$
\begin{gathered}
\frac{M_{c} G_{c}}{M_{c} H_{c}}=\frac{M_{c} G}{M_{c} C}=\frac{G_{c} G}{H_{C} C}=\frac{1}{3} \\
A G_{C}=A M_{C}-G M_{C}=\frac{1}{2} A B-\frac{1}{3} M_{c} H_{c}=\frac{1}{2} c-\frac{1}{3}\left(A M_{c}-A H_{c}\right) \\
=\frac{1}{2} c-\frac{1}{3}\left(\frac{1}{2} c-\frac{b^{2}+c^{2}-a^{2}}{2 c}\right) \\
=\frac{3 c^{2}-c^{2}+b^{2}+c^{2}-a^{2}}{6 c}=\frac{3 c^{2}+b^{2}-a^{2}}{6 c} \\
G_{c} G=\frac{1}{3} H_{c} C=\frac{1}{3} C H_{c}=\frac{2(A B C)}{3}
\end{gathered}
$$

Portanto, as coordenadas cartesianas do CENTRÓIDE são:

$$
\begin{gathered}
x_{G}=\frac{3 c^{2}+b^{2}-a^{2}}{6 c} \\
y_{G}=\frac{2}{3} \frac{(A B C)}{c}
\end{gathered}
$$


Retomando o assunto tratado no Capítulo 2, o centróide $(G)$ também é ponto de mínimo da função distância de um ponto interno aos três vértices do triângulo. Seja um triângulo $A B C$, com o vértice $A$ na origem e o lado $A B$ sobre o eixo das abscissas. Designamos por $(\mathrm{d}, \mathrm{e})$ as coordenadas do vértice $\mathrm{C}$.

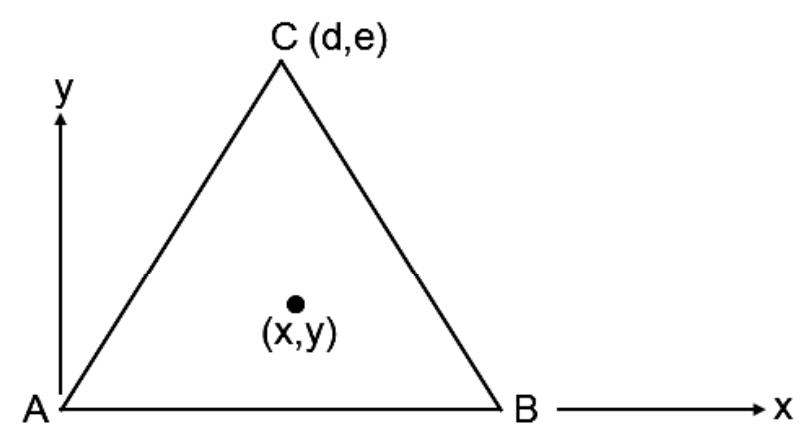

Figura 26 - Triângulo construído no plano cartesiano em posição especial

$$
f(x, y)=x^{2}+y^{2}+(x-c)^{2}+y^{2}+(x-d)^{2}+(y-e)^{2}
$$

Desenvolvendo a equação e completando quadrados,obtém-se,

$$
f(x, y)=3\left(x-\frac{c+d}{3}\right)^{2}+3\left(y-\frac{e}{3}\right)^{2}+c^{2}+d^{2}+e^{2}-\frac{(c+d)^{2}}{3}-\frac{e^{2}}{3}
$$

Como $c^{2}+d^{2}+e^{2}-\frac{(c+d)^{2}}{3}-\frac{e^{2}}{3}$ é constante, verifica-se para que a função seja mínima quando,

$$
x=\frac{c+d}{3} \text { e } y=\frac{e}{3}
$$

\section{AS COORDENADAS CARTESIANAS DO CIRCUNCENTRO (0)}

$$
x_{o}=\frac{c}{2} \quad y_{o}=\frac{c\left(a^{2}+b^{2}-c^{2}\right)}{8(A B C)}
$$


Passamos agora ao cálculo das coordenadas cartesianas do circuncentro $(O)$

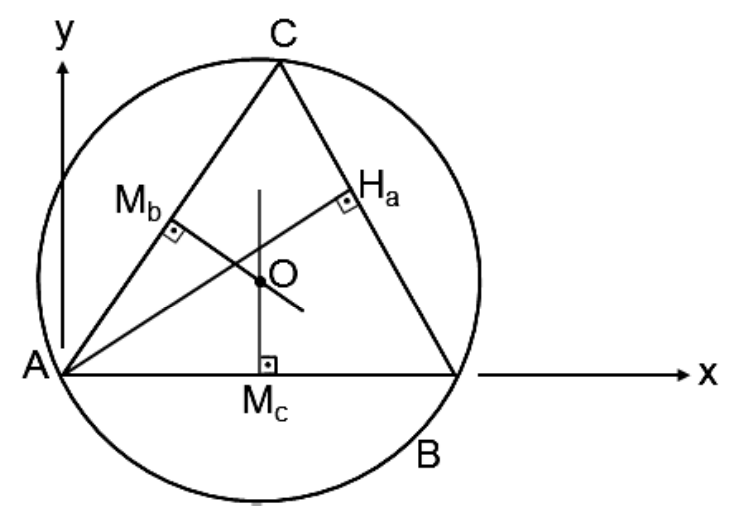

Figura 27. Ponto O, encontro das mediatrizes

$$
A H_{a}=\frac{2(A B C)}{a}
$$

Pela lei dos cossenos,

$$
\begin{gathered}
c^{2}=a^{2}+b^{2}-2 b c \cos \hat{C}=a^{2}+b^{2}-2 a C H_{a} \\
C H_{a}=\frac{a^{2}+b^{2}-c^{2}}{2 a}
\end{gathered}
$$

em relação aos triângulos semelhantes $-\triangle A C H_{a} \sim \triangle A O M_{C}$

$$
\begin{gathered}
\frac{A C}{A O}=\frac{A H_{a}}{A M_{C}}=\frac{C H_{a}}{O M_{c}} \\
O M_{c}=\frac{A M_{c} \cdot C H_{a}}{A H_{a}}=\frac{c\left(a^{2}+b^{2}-c^{2}\right)}{8(A B C)}
\end{gathered}
$$

portanto as coordenadas cartesianas do CIRCUNCENTRO são:

$$
\begin{gathered}
x_{o}=\frac{c}{2} \\
y_{o}=\frac{c\left(a^{2}+b^{2}-c^{2}\right)}{8(A B C)}
\end{gathered}
$$




\subsection{Cálculo das Distâncias entre os Pontos Colineares - Ortocentro,}

\section{Circuncentro e Centróide}

DISTÂNCIA DE ORTOCENTRO $(H)$ A CENTROIDE $(G)$

$$
H G^{2}=\frac{\left(b^{2}-a^{2}\right)^{2}}{9 c^{2}}+\frac{16(A B C)^{2}}{9 c^{2}}-\frac{2 a^{2}+2 b^{2}+c^{2}}{3}+\frac{a^{2} b^{2} c^{2}}{4(A B C)^{2}}
$$

Prova:

$$
\begin{gathered}
H G^{2}=\left[\frac{b^{2}+c^{2}-a^{2}}{2 c}-\frac{3 c^{2}+b^{2}-a^{2}}{6 c}\right]^{2}+\left[\frac{2(A B C)}{c}+\frac{c\left(c^{2}-a^{2}-b^{2}\right)}{4(A B C)}-\frac{2(A B C)}{3 c}\right]^{2} \\
H G^{2}=\left(\frac{b^{2}-a^{2}}{3 c}\right)^{2}+\left[\frac{4(A B C)}{3 c}+\frac{c\left(c^{2}-a^{2}-b^{2}\right)}{4(A B C)}\right]^{2} \\
=\frac{\left(b^{2}-a^{2}\right)^{2}}{9 c^{2}}+\frac{16(A B C)^{2}}{9 c^{2}}-\frac{2 a^{2}+2 b^{2}+c^{2}}{3}+\frac{a^{2} b^{2} c^{2}}{4(A B C)^{2}}
\end{gathered}
$$

DISTÂNCIA DE ORTOCENTRO A CIRCUNCENTRO

$$
O H^{2}=\frac{\left(b^{2}-a^{2}\right)^{2}+16(A B C)^{2}}{4 c^{2}}-\frac{6 a^{2}+6 b^{2}+3 c^{2}}{4}+\frac{9 a^{2} b^{2} c^{2}}{16(A B C)^{2}}
$$

Prova:

$$
\begin{gathered}
O H^{2}=\left(\frac{b^{2}+c^{2}-a^{2}}{2 c}-\frac{c}{2}\right)^{2}+\left[\frac{2(A B C)}{c}+\frac{c\left(c^{2}-a^{2}-b^{2}\right)}{4(A B C)}-\frac{c\left(a^{2}+b^{2}-c^{2}\right)}{8(A B C)}\right]^{2} \\
O H^{2}=\frac{\left(b^{2}-a^{2}\right)^{2}+16(A B C)^{2}}{4 c^{2}}-\frac{6 a^{2}+6 b^{2}+3 c^{2}}{4}+\frac{9 a^{2} b^{2} c^{2}}{16(A B C)^{2}}
\end{gathered}
$$




$$
O G^{2}=\frac{\left(b^{2}-a^{2}\right)^{2}+16(A B C)^{2}}{36 c^{2}}-\frac{2 a^{2}+2 b^{2}+c^{2}}{12}+\frac{a^{2} b^{2} c^{2}}{16(A B C)^{2}}
$$

Prova:

$$
\begin{aligned}
& O G^{2}=\left(\frac{3 c^{2}+b^{2}-a^{2}}{6 c}-\frac{c}{2}\right)^{2}+\left[\frac{2(A B C)}{3 c}-\frac{c\left(a^{2}+b^{2}-c^{2}\right)}{8(A B C)}\right]^{2} \\
& O G^{2}=\frac{\left(b^{2}-a^{2}\right)^{2}+16(A B C)^{2}}{36 c^{2}}-\frac{2 a^{2}+2 b^{2}+c^{2}}{12}+\frac{a^{2} b^{2} c^{2}}{16(A B C)^{2}}
\end{aligned}
$$

Leonard Euler (1707 - 1783), matemático suíço, um dos mais brilhantes da história, descobriu que o ortocentro, o centróide e o circuncentro de um triângulo qualquer são colineares. A reta que contém esses pontos é, por isso, designada reta de Euler. O ortocentro, o baricentro e o circuncentro estão alinhados e sempre apresentam a mesma proporção. Essa reta ainda contém o centro da circunferência dos nove pontos, dentre outros pontos.

É válido notar que tendo as coordenadas, é possível verificar a colinearidade entre os pontos $\mathrm{G}, \mathrm{O}$ e H, que é a reta de Euler, e sua proporção. Então:

$$
\begin{gathered}
G H^{2}=4 O G^{2} \\
O H^{2}=9 O G^{2} \\
d=O G \\
G H=2 O G \\
O H=3 O G \\
O H=3 O G=2 O G+O G=G H+O G
\end{gathered}
$$




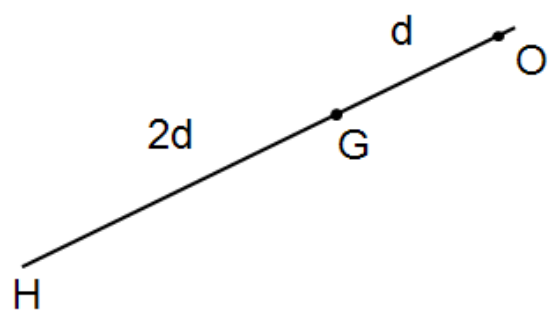

Figura 28. Reta de Euler é a reta determinada pelos pontos colineares $\boldsymbol{G}, \boldsymbol{H}$ e $\boldsymbol{O}$

Para finalizar este capítulo, vamos apresentar as coordenadas dos pontos sobre os lados do triângulo que estão relacionados com os pontos notáveis. Duas observações que se fazem necessárias são:

- a coordenada do ponto C é (d,e); e

- para a determinação das coordenadas das intersecções das bissetrizes com os respectivos lados opostos, a utilização das medidas dos lados do triângulo, a e b, foram necessárias para facilitar a compreensão.

Seja o triângulo $\triangle A B C$, na posição especial.

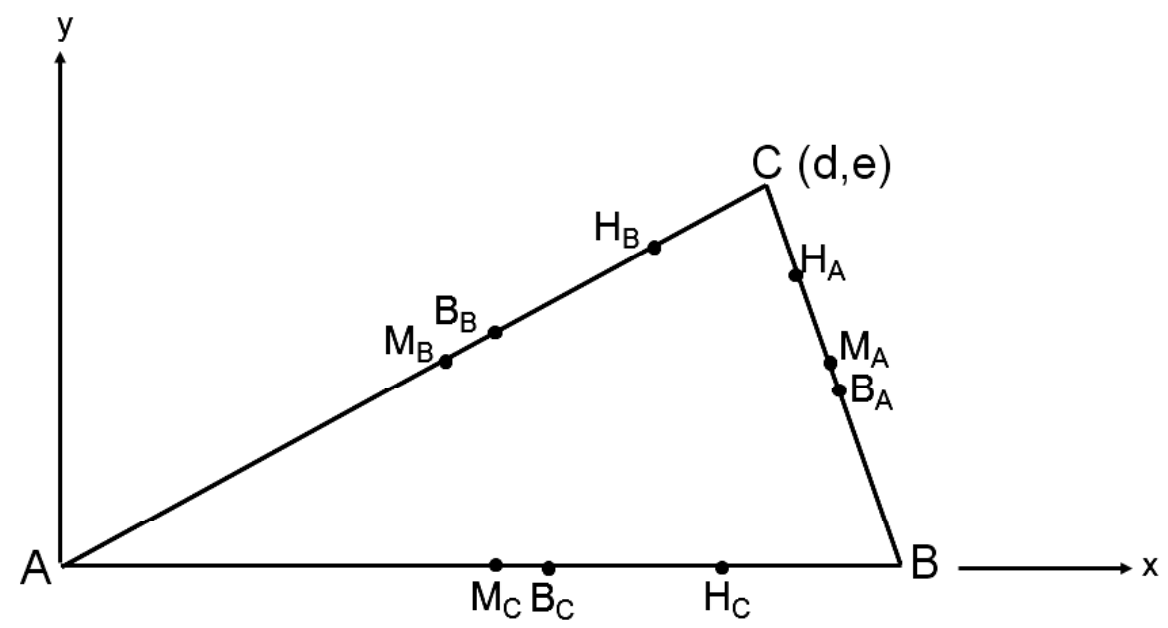

Figura 29. Pontos $H_{A}, H_{B}, H_{C}, M_{A}, M_{B}, M_{C}, B_{A}, B_{B} e B_{C}$

As coordenadas das intersecções das medianas e dos lados opostos $\left(M_{A}, M_{B} e M_{C}\right)$, são as as coordenadas mais simples de se obter. Para isso, basta calcular o ponto médio de cada lado do triângulo. 
As coordenadas cartesianas dos pontos médios dos lados são,

$$
\begin{gathered}
M_{A}=\left(\frac{c+d}{2}, \frac{e}{2}\right) \\
M_{B}=\left(\frac{d}{2}, \frac{e}{2}\right) \\
M_{C}=\left(\frac{c}{2}, 0\right)
\end{gathered}
$$

Para determinar as coordendadas cartesianas dos pontos de intersecção da bissetriz do ângulo interno e o lado oposto $\left(B_{A}, B_{B} e B_{c}\right)$, é necessária a utilização do Teorema das Bissetrizes Internas e uma semelhança de triângulo, nessa última, usando sempre triângulos retângulos formados pelo vértice $\mathrm{C}$ e o lado sobre o eixo da abscissa, e triângulos com o vértice na intersecção da bissetriz e o lado oposto e o lado sobre o eixo da abscissa.

As coordenadas são:

$$
\begin{gathered}
B_{A}=\left(\frac{c(b+d)}{b+c}, \frac{c e}{b+c}\right) \\
B_{B}=\left(\frac{c d}{a+c}, \frac{c e}{a+c}\right) \\
B_{C}=\left(\frac{b c}{a+b}, 0\right)
\end{gathered}
$$

E para determinar as coordenadas dos "pés" destas alturas $\left(H_{A}, H_{B} e H_{C}\right)$, utiliza-se o Teorema de Pitágoras nos dois triângulos retângulos obtidos pela altura e faz-se a determinação resolvendo o sistema de incógnitas.

As coordenadas cartesianas dos "pés da altura", são:

$$
\begin{gathered}
H_{A}=\left(\frac{e^{2} c}{e^{2}+(c-d)^{2}}, \frac{c e(c-d)}{e^{2}+(c-d)^{2}}\right) \\
H_{B}=\left(\frac{c d^{2}}{d^{2}+e^{2}}, \frac{c d e}{d^{2}+e^{2}}\right) \\
H_{C}=(d, 0)
\end{gathered}
$$


4 Os Pontos Notáveis de um Triângulo como Números Complexos

Neste capítulo, para as demonstrações com números complexos, usaremos o plano de Argand-Gauss, onde as letras maiúsculas $A, B, \ldots$, corespondem a números complexos ou pontos do plano, sendo cada ponto $(x, y)$ identificado como $x+$ iy. A "posição especial" que será adotada como referência é a de que o circuncentro $(O)$ do triângulo $\triangle A B C$ coincide com a origem do plano complexo de Argand-Gauss. Assim $A, B$ e $C$ são números complexos, cujos módulos são todos iguais ao raio $(R)$ da circunferência circunscrita ao triângulo $\triangle A B C$ :

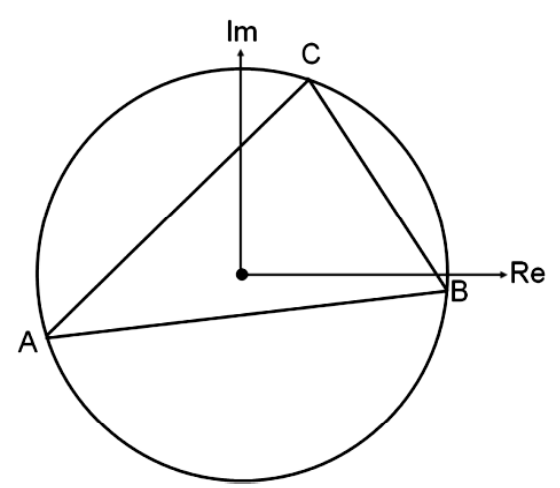

Figura 30. Triângulo no plano de Argand - Gauss.

O centróide $(G)$ do triângulo $\triangle A B C$ é o número complexo,

$$
G=\frac{1}{3}(A+B+C)
$$

Prova: Sabe-se que $\overrightarrow{A G}=2 \overrightarrow{G M}$, e M é o ponto médio do lado BC, logo:

$$
\begin{gathered}
G-A=2(M-G) \\
G-A=2\left(\frac{B+C}{2}\right)-2 G \\
G=\frac{1}{3}(A+B+C)
\end{gathered}
$$


Pode parecer que os números complexos não foram utilizados nas equações acima, no entanto, vale lembrar que a soma e a multiplicação de um número complexo por um numero real funciona como vetores. A inovação no plano dos complexos em relação ao plano cartesiano é a possibilidade do produto entre complexos.

Para determinar a localização do Ortocentro $(\mathrm{O})$, do Circuncentro $(\mathrm{C})$ e do Centro da Circunferência dos Nove Pontos $(\mathrm{N})$, primeiro será necessário definir a condição de alinhamento de três pontos, bem como a equação de retas paralelas e perpendiculares.

\subsection{Condição de Alinhamento de Três Pontos (A, B e C) no Plano Complexo com Coordenadas $A\left(X_{a}, Y_{a}\right) B\left(X_{b}, Y_{b}\right)$ e $C\left(X_{c}, Y_{c}\right)$}

Para que os pontos $A, B$ e $C$ estejam alinhados é necessário e suficiente que $(\mathrm{B}-\mathrm{A})=\alpha(\mathrm{C}-\mathrm{B})$, onde $\alpha \in \mathbb{R}$, ou seja, os vetores $\overrightarrow{\mathrm{AB}}$ e $\overrightarrow{\mathrm{BC}}$ são paralelos, com isso $\frac{(B-A)}{(C-B)}$ é real e assim:

$$
\begin{gathered}
\frac{\mathrm{B}-\mathrm{A}}{\mathrm{C}-\mathrm{B}}=\frac{\overline{\mathrm{B}}-\overline{\mathrm{A}}}{\overline{\mathrm{C}}-\overline{\mathrm{B}}} \Leftrightarrow \\
\left|\begin{array}{lll}
\mathrm{A} & \overline{\mathrm{A}} & 1 \\
\mathrm{~B} & \overline{\mathrm{B}} & 1 \\
\mathrm{C} & \overline{\mathrm{C}} & 1
\end{array}\right|=0 \Leftrightarrow\left|\begin{array}{lll}
\mathrm{x}_{\mathrm{a}} & \mathrm{y}_{\mathrm{a}} & 1 \\
\mathrm{x}_{\mathrm{b}} & \mathrm{y}_{\mathrm{b}} & 1 \\
\mathrm{x}_{\mathrm{c}} & \mathrm{y}_{\mathrm{c}} & 1
\end{array}\right|=0
\end{gathered}
$$

Equação da reta determinada por dois números complexos distintos (A e B)

Dados dois pontos $A$ e $B$, a equação da reta que passa por esses pontos satisfaz:

$$
\begin{gathered}
\frac{\mathrm{Z}-\mathrm{A}}{\mathrm{B}-\mathrm{A}}=\frac{\overline{\mathrm{Z}}-\overline{\mathrm{A}}}{\overline{\bar{B}}-\overline{\mathrm{A}}} \\
\left|\begin{array}{lll}
\mathrm{Z} & \overline{\mathrm{Z}} & 1 \\
\mathrm{~A} & \overline{\mathrm{A}} & 1 \\
\mathrm{~B} & \overline{\mathrm{B}} & 1
\end{array}\right| \Leftrightarrow\left|\begin{array}{lll}
\mathrm{x}_{\mathrm{z}} & \mathrm{y}_{\mathrm{z}} & 1 \\
\mathrm{x}_{\mathrm{a}} & \mathrm{y}_{\mathrm{a}} & 1 \\
\mathrm{x}_{\mathrm{b}} & \mathrm{y}_{\mathrm{b}} & 1
\end{array}\right|=0
\end{gathered}
$$


A equação fica:

$$
\frac{Z}{(A-B)}-\frac{\bar{Z}}{(\bar{A}-\bar{B})}=\frac{A}{A-B}-\frac{\bar{A}}{\bar{A}-\bar{B}}
$$

que é equivalente a

$$
\mathrm{Z}(\overline{\mathrm{A}}-\overline{\mathrm{B}})-\overline{\mathrm{Z}}(\mathrm{A}-\mathrm{B})=\mathrm{A}(\overline{\mathrm{A}}-\overline{\mathrm{B}})-\overline{\mathrm{A}}(\mathrm{A}-\mathrm{B})
$$

Pensando no caso particular em que $|\mathrm{A}|=|\mathrm{B}|=1$, e $\overline{\mathrm{A}}=\frac{1}{\mathrm{~A}}$ e $\overline{\mathrm{B}}=\frac{1}{\mathrm{~B}}$. Teremos:

$$
\mathrm{Z}+\mathrm{AB} \overline{\mathrm{Z}}=\mathrm{A}+\mathrm{B}
$$

Reta paralela a $\overleftrightarrow{A B}$ e passando por C:

$$
\frac{\mathrm{Z}}{(\mathrm{A}-\mathrm{B})}-\frac{\overline{\mathrm{Z}}}{(\overline{\mathrm{A}}-\overline{\mathrm{B}})}=\frac{\mathrm{C}}{\mathrm{A}-\mathrm{B}}-\frac{\overline{\mathrm{C}}}{\overline{\mathrm{A}}-\overline{\mathrm{B}}}
$$

que é equivalente a

$$
\mathrm{Z}(\overline{\mathrm{A}}-\overline{\mathrm{B}})-\overline{\mathrm{Z}}(\mathrm{A}-\mathrm{B})=\mathrm{C}(\overline{\mathrm{A}}-\overline{\mathrm{B}})-\overline{\mathrm{C}}(\mathrm{A}-\mathrm{B})
$$

\section{Reta Ortogonal}

Dados $A$ e $B$, a equação da reta s ortogonal a $B$ e passando por $A$ é tal que se $Z \in s$, então $\frac{Z-A}{B}$ é um imaginário puro e assim $\frac{Z-A}{B}+\frac{\bar{Z}-\bar{A}}{\bar{B}}=0$, ou seja,

$$
\begin{gathered}
\frac{\mathrm{Z}}{\mathrm{A}-\mathrm{B}}+\frac{\overline{\mathrm{Z}}}{\overline{\mathrm{A}}-\overline{\mathrm{B}}}=\frac{\mathrm{Z}_{0}}{\mathrm{~A}-\mathrm{B}}+\frac{\overline{\mathrm{Z}}_{0}}{\overline{\mathrm{A}}-\overline{\mathrm{B}}} \\
u=\frac{A+B / 2}{|A+B| / 2}=\frac{A+B}{|A+B|} \\
\frac{\mathrm{Z}}{\mathrm{u}}+\frac{\overline{\mathrm{Z}}}{\overline{\mathrm{u}}}=\frac{\mathrm{Z}_{0}}{\mathrm{u}}+\frac{\overline{\mathrm{Z}}_{0}}{\overline{\mathrm{u}}}
\end{gathered}
$$

Para três pontos dados $\mathrm{A}, \mathrm{B}$ e $\mathrm{C}$, a equação da reta perpendicular à reta $\overleftrightarrow{A B}$ e passando por $\mathrm{C}$ é:

$$
\frac{\mathrm{Z}}{\mathrm{A}-\mathrm{B}}+\frac{\overline{\mathrm{Z}}}{\overline{\mathrm{A}}-\overline{\mathrm{B}}}=\frac{\mathrm{C}}{\mathrm{A}-\mathrm{B}}+\frac{\overline{\mathrm{C}}}{\overline{\mathrm{A}}-\overline{\mathrm{B}}}
$$

que é equivalente a

$$
\mathrm{Z}(\overline{\mathrm{A}}-\overline{\mathrm{B}})+\overline{\mathrm{Z}}(\mathrm{A}-\mathrm{B})=\mathrm{C}(\overline{\mathrm{A}}-\overline{\mathrm{B}})+\overline{\mathrm{C}}(\mathrm{A}-\mathrm{B})
$$




\subsection{Equação da Reta Mediatriz dos Números Complexos Distintos A e B}

A mediatriz é a reta perpendicular à reta $\overleftrightarrow{A B}$, passando por $\frac{A+B}{2}$, utilizando (5) encontra-se a equação da mediatriz.

$$
Z(\overline{\mathrm{A}}-\overline{\mathrm{B}})+\overline{\mathrm{Z}}(\mathrm{A}-\mathrm{B})=\left(\frac{\mathrm{A}+\mathrm{B}}{2}\right)(\overline{\mathrm{A}}-\overline{\mathrm{B}})+\left(\frac{\overline{\mathrm{A}}+\overline{\mathrm{B}}}{2}\right)(\mathrm{A}-\mathrm{B})
$$

Simplificando

$$
\mathrm{Z}(\overline{\mathrm{A}}-\overline{\mathrm{B}})+\overline{\mathrm{Z}}(\mathrm{A}-\mathrm{B})=|\mathrm{A}|^{2}-|\mathrm{B}|^{2}
$$

Para obter a equação da reta mediatriz, basta calcular o determinante da matriz $3 \times 3$, dos pontos $A$ e $B$ com o ponto $Z$, com $Z$ sendo o ponto médio de $\overleftrightarrow{A B}$. Reorganizando a equação (6), obtém-se:

$$
\left|\begin{array}{lll}
Z & \bar{Z} & 1 \\
A & \bar{B} & 1 \\
B & \bar{A} & 1
\end{array}\right|=0
$$

\subsection{Equação do Feixe de Retas Perpendiculares no Plano Complexo a Uma Reta Dada r.}

Com o resultado dessa equação, podemos determinar as coordenadas do ortocentro e ainda auxiliar na demonstração da circunferência dos nove pontos.

Lembrando que $\left(Z_{2}-Z_{1}\right) \perp\left(Z_{3}-Z_{1}\right) \Leftrightarrow \frac{Z_{2}-Z_{1}}{Z_{3}-Z_{1}}$, for imaginário puro.

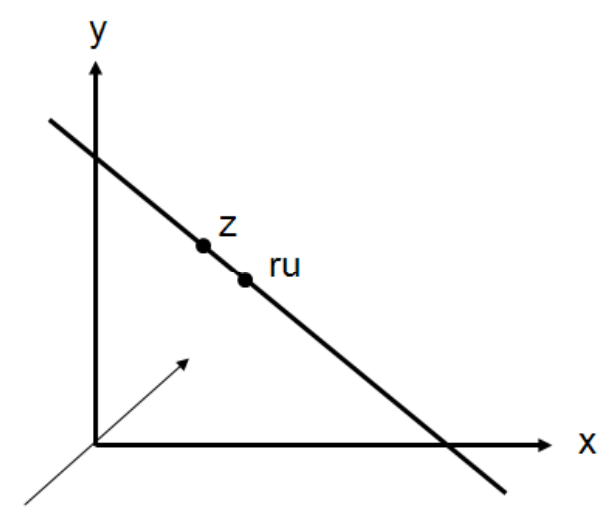

Figura 30

Seja $u \in \mathbb{C}$, com $|u|=1$ e ué perpendicular a reta $r$ dada. 
s é a distância da origem até a reta;

Usando a equação (4), temos:

$$
\frac{z}{i u}+\frac{\bar{z}}{-\overline{i u}}=2 s, \text { para algum } s \in \mathbb{R} .
$$

multiplicando a equação por i, obtemos:

$$
\frac{z}{u}-\frac{\bar{z}}{\bar{u}}=2 i s, \text { para algum } s \in \mathbb{R}
$$

Após a determinação das equações das retas, é possível determinar o ortocentro o circuncentro e o centro da circunferência dos nove pontos.

\section{ORTOCENTRO}

O ortocentro $(H)$ do triângulo $\triangle A B C$, na posição especial, é o número complexo

$$
H=A+B+C
$$

Prova: De acordo com a equação (5), a altura relativa ao vértice $A$, é dada por:

$$
\mathrm{Z}(\overline{\mathrm{B}}-\overline{\mathrm{C}})+\overline{\mathrm{Z}}(\mathrm{B}-\mathrm{C})=\mathrm{A}(\overline{\mathrm{B}}-\overline{\mathrm{A}})+\overline{\mathrm{A}}(\mathrm{B}-\mathrm{C})
$$

De modo análogo obtemos as outras equações das alturas.

$$
\begin{gathered}
\mathrm{Z}(\overline{\mathrm{A}}-\overline{\mathrm{C}})+\overline{\mathrm{Z}}(\mathrm{A}-\mathrm{C})=\mathrm{B}(\overline{\mathrm{A}}-\overline{\mathrm{C}})+\overline{\mathrm{B}}(\mathrm{A}-\mathrm{C}) \\
\mathrm{Z}(\overline{\mathrm{A}}-\overline{\mathrm{B}})+\overline{\mathrm{Z}}(\mathrm{A}-\mathrm{B})=\mathrm{C}+\overline{\mathrm{C}}(\mathrm{A}-\mathrm{B})
\end{gathered}
$$

As três equações encontradas são combinações lineares umas das outras, então o ponto de intersecção entre duas pertence à outra equação.

Isolando $\bar{Z}$ em (c) e (a), obteremos respectivamente:

$$
\begin{aligned}
& \overline{\mathrm{Z}}=\frac{1}{\mathrm{C}}-\frac{\mathrm{C}}{\mathrm{AB}}+\frac{\mathrm{Z}}{\mathrm{AB}} \quad(d) \\
& \overline{\mathrm{Z}}=\frac{1}{\mathrm{~A}}-\frac{\mathrm{A}}{\mathrm{BC}}+\frac{\mathrm{Z}}{\mathrm{BC}} \quad(e)
\end{aligned}
$$


Igualando (d) e (e), chega-se a:

$$
Z=A+B+C
$$

Como Z, neste caso, representa o encontro das alturas, Z é o ortocentro do triângulo.

\section{CIRCUNCENTRO}

O circuncentro $(O)$ de um triângulo $\triangle A B C$ qualquer, é o número complexo,

$$
O=\frac{|A|^{2}(B-C)+|B|^{2}(C-A)+|C|^{2}(A-B)}{\bar{A}(B-C)+\bar{B}(C-A)+\bar{C}(A-B)}
$$

Para determinar as coordenadas complexas do circuncentro usaremos a equação (6). As mediatrizes dos lados $A B, C A$ e $B C$, são respectivamente:

$$
\begin{aligned}
& \mathrm{Z}(\overline{\mathrm{A}}-\overline{\mathrm{B}})+\overline{\mathrm{Z}}(\mathrm{A}-\mathrm{B})=|\mathrm{A}|^{2}-|\mathrm{B}|^{2} \\
& \mathrm{Z}(\overline{\mathrm{C}}-\overline{\mathrm{A}})+\overline{\mathrm{Z}}(\mathrm{C}-\mathrm{A})=\left.\left|\mathrm{C}^{2}-\right| \mathrm{A}\right|^{2} \\
& \mathrm{Z}(\overline{\mathrm{B}}-\overline{\mathrm{C}})+\overline{\mathrm{Z}}(\mathrm{B}-\mathrm{C})=|\mathrm{B}|^{2}-\mid \mathrm{C}^{2}
\end{aligned}
$$

Somando duas das equações obtemos a terceira, de modo que podemos concluir que a intersecção entre duas equações está na terceira equação da mediatriz. Para determinar as coordenadas, basta isolar $\bar{Z}$ em uma equação e substituir numa das outras equações acima. Assim, isolando $\bar{Z}$ da equação (h),

$$
\bar{Z}=\frac{|\mathrm{B}|^{2}-\mid \mathrm{Cl}^{2}-(\overline{\mathrm{B}}-\overline{\mathrm{C}}) \mathrm{Z}}{\mathrm{B}-\mathrm{A}}
$$

e substituindo na equação (g), temos:

$$
\begin{gathered}
(\bar{C}-\bar{A}) Z+(C-A)\left(\frac{|\mathrm{B}|^{2}-\mid \mathrm{C}^{2}-(\overline{\mathrm{B}}-\overline{\mathrm{C}}) \mathrm{Z}}{\mathrm{B}-\mathrm{A}}\right)=\left.\left|\mathrm{C}^{2}-\right| \mathrm{A}\right|^{2} \Rightarrow \\
(B-A)(\bar{C}-\bar{A}) Z+(C-A)\left(|\mathrm{B}|^{2}-\mid \mathrm{C}^{2}\right)-(C-A)(\overline{\mathrm{B}}-\overline{\mathrm{C}}) \mathrm{Z}=(B-A)\left(\left.\left|\mathrm{C}^{2}-\right| \mathrm{A}\right|^{2}\right) \Rightarrow \\
Z=\frac{|A|^{2}(B-C)+|B|^{2}(C-A)+|C|^{2}(A-B)}{\bar{A}(B-C)+\bar{B}(C-A)+\bar{C}(A-B)}
\end{gathered}
$$


Como Z representa o encontro das mediatrizes, então $Z$ é o circuncentro do triângulo. Por simetria, é possível verificar que a equação encontrada para Z também satisfaz a equação (f).

\subsection{O Teorema da Circunferência dos Nove Pontos}

Antes de determinar as coordenadas complexas da circunferência dos nove pontos, será demonstrado esse teorema.

A circunferência dos nove pontos é creditada a Karl W. Feuerbach (1800 1834), sendo também conhecida como círculo de Feuerbach. No entanto, outros creditam a sua descoberta a Euler, que já conhecia algumas de suas propriedades, e outros creditam a Poncelet (1788 - 1867), que publicou a circunferência um ano antes de Feuerbach. Porém, foi Feuerbach quem descobriu que essa circunferência passava por seis pontos e descobriu também que essa circunferência era tangente exterior a circunferências exinscritas; (esse Teorema está descrito no final do capítulo, juntamente com outras propriedades).

O centro $(\mathrm{N})$ dos nove pontos desta circunferência fica no meio da reta de Euler, entre o ortocentro e o circuncentro, sendo o ponto médio de $\mathrm{HO}$.

A circunferência dos nove pontos, em um triângulo $A B C$, passa pelos seguintes pontos:

- as três projeções ortogonais dos três vértices do triângulo aos lados opostos(D,E e F);

- os três pontos médios dos três lados do triângulo(J,K e L);

- os pontos médios dos três segmentos cujos extremos são o ortocentro e um dos três vértices ( $M, P$ e Q); 
Estes pontos estão sobre a mesma circunferência, cujo centro $N$ é o ponto médio do segmento cujos extremos são o ortocentro $(H)$ e o circuncentro $(O)$, e cujo raio é a metade do raio da circunferência circunscrita ao triângulo $A B C$.

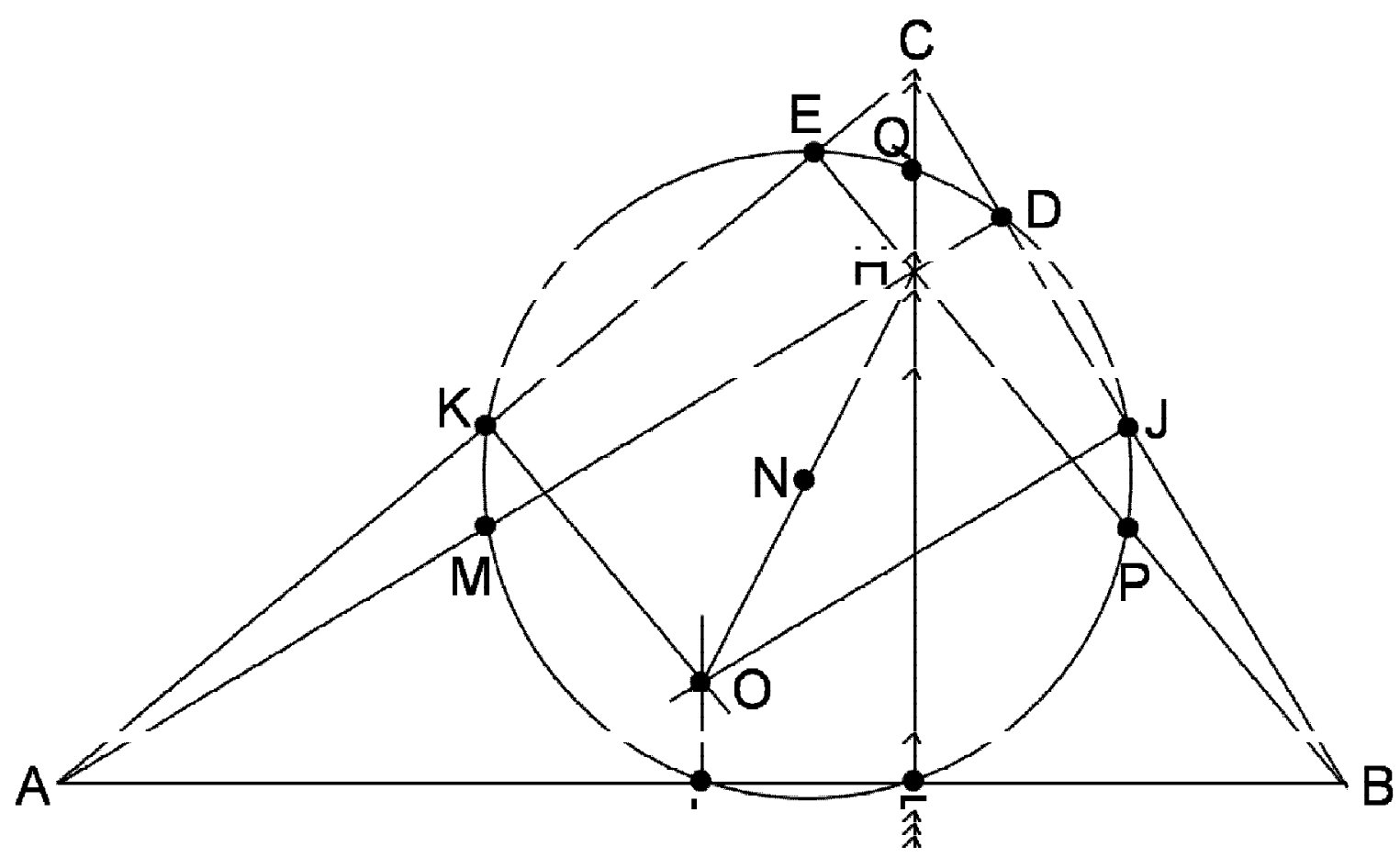

Figura 31. Circunferência dos nove pontos.

Prova:

- Existe uma única circunferência que passa pelos pontos $\mathrm{J}, \mathrm{K}$ e $\mathrm{L}$, pois por três pontos distintos e não colineares existe uma única circunferência passando por eles.

- $\mathrm{O}$ segmento $\mathrm{KJ}$ é base média de $\mathrm{AB} ;(\mathrm{AB}=2 \mathrm{KJ})$

- L é ponto médio da hipotenusa do triângulo retângulo $\triangle B D A$, logo $\mathrm{AB}=2 \mathrm{LD}$

- Concluímos que $\mathrm{KJ}=\mathrm{LD}$ e que o trapézio DKLJ é isósceles, pois suas diagonais possuem a mesma medida; todo trapézio isósceles é inscritível, assim a circunferência que contém os pontos $\mathrm{J}, \mathrm{K}$ e $\mathrm{L}$ 
também contém o ponto $\mathrm{D}$; de modo análogo podemos provar que a circunferência passa também pelos pontos $\mathrm{E}$ e $\mathrm{F}$.

- Provamos até aqui que existe uma circunferência única que passa pelos pontos $\mathrm{J}, \mathrm{K}, \mathrm{L}, \mathrm{D}, \mathrm{E}$ e $\mathrm{F}$, falta provar que também passa pelos pontos $M, P$ e $Q$.

- Agora considerando o triângulo $\triangle B H C$, os pontos $\mathrm{D}$, E e F são também os "pés da altura" desse triângulo, assim QP é base média de BC, logo $\mathrm{BC}=2 \mathrm{QP}$

- Observando o triângulo retângulo $\triangle B E C$, J é o ponto médio da hipotenusa, assim $\mathrm{BC}=2 \mathrm{EJ}$; se observarmos o triângulo retângulo $\triangle B F C$, da mesma forma como observado anteriormente, temos $\mathrm{BC}=2 \mathrm{FJ}$

- Conclui-se que QP = EJ = FJ, assim os trapézios EPJQ e QJPF são isósceles e assim a circunferência que passa pelos pontos $D$, E e $F$ também passa pelos pontos $\mathrm{M}, \mathrm{P}$ e $\mathrm{Q}$.

Assim obtemos os nove pontos da circunferência.

Para determinar o centro da circunferência dos nove pontos, basta tomar o quadrilátero KJPM, que é um retângulo, pois $\mathrm{KJ}$ e MP são paralelos ao lado $\mathrm{AB}$ e bases médias dos triângulo $\triangle A B C$ e $\triangle A H B$ respectivamente; da mesma forma $\mathrm{KM}$ e JP são paralelos à altura CF e bases médias dos triângulos $\triangle A C H$ e $\triangle B C H$, respectivamente. Além disso, os lados KJ e MP são perpendiculares aos lados KM e JP, uma vez que $A B$ é perpendicular à $C F$. Como os ponto $K$ e $P$ estão diametralmente opostos, a intersecção das diagonais desse retângulo é o centro da circunferência, sendo esse ponto o ponto N. O raio da circunferência dos nove pontos é a metade do raio da circunferência circunscrita ao triângulo. 
Para determinarmos as coordenadas do centro da circunferência dos nove pontos, vale lembrar que as distâncias entre o número complexo $N$ e os nove pontos são constantes e iguais a $\frac{R}{2}$, em que $R$ é o raio da circunferência circunscrita ao triângulo.

O centro da circunferência dos nove pontos $(N)$ do triângulo $\triangle A B C$, na posição especial é o número complexo,

$$
N=\frac{1}{2}(A+B+C)
$$

Para a verificação desta coordenada, basta lembrar que $\mathrm{N}$ é equidistante de $\mathrm{O}$ e $\mathrm{H}$, como $\mathrm{O}$ foi fixado na origem do plano, o valor de $\mathrm{N}$ é o ponto médio de $\mathrm{O}$ e $\mathrm{H}$.

Uma outra maneira de demonstrar as coordenadas do centro, é considerar o triângulo formado pelos pontos médios do $\triangle A B C$, no qual a circunferência dos nove pontos circunscreve esse triângulo, de modo que, utilizando a equação (7), temos:

$$
Z=\frac{\left|\frac{A+B}{2}\right|^{2}\left(\frac{B+C}{2}-\frac{A+C}{2}\right)+\left|\frac{B+C}{2}\right|^{2}\left(\frac{A+C}{2}-\frac{A+B}{2}\right)+\left|\frac{A+C}{2}\right|^{2}\left(\frac{A+B}{2}-\frac{B+C}{2}\right)}{\frac{\bar{A}+\bar{B}}{2}\left(\frac{B+C}{2}-\frac{A+C}{2}\right)+\frac{\bar{B}+\bar{C}}{2}\left(\frac{A+C}{2}-\frac{A+B}{2}\right)+\frac{\bar{B}+\bar{C}}{2}\left(\frac{A+B}{2}-\frac{B+C}{2}\right)}
$$

Resolvendo chega-se a:

$$
Z=\frac{1}{2}(A+B+C)
$$

TEOREMA 4.4.1: A circunferência de nove pontos do triângulo $\triangle A B C$ é a circunferência dos nove pontos dos três triângulos: $\triangle H B C, \triangle H C A$ e $\triangle H A B$.

Tomando o triângulo $\triangle H A B$ :

- D, E e F são os "pés" da alturas dos lados BH, $\mathrm{AH}$ e AB;

- Os pontos médios desse triângulo são $\mathrm{P}, \mathrm{M}$ e L, respectivamente, dos lados $\mathrm{BH}, \mathrm{AH}$ e $\mathrm{AB}$; 
- Por fim, os pontos K, J e Q são os pontos médios do segmento que tem as extremidades no ortocentro, neste caso o ponto $\mathrm{C}$, e os vértices do triângulo.

Pela construção verifica-se que a circunferência passa por esses pontos. Para os outros triângulos a verificação é da mesma maneira.

\subsection{Equação da reta determinada por dois números complexos distintos $\mathrm{A}$ e $\mathrm{B}$.}

Para os casos abaixo iremos considerar que os complexos possuem mesmo módulo.

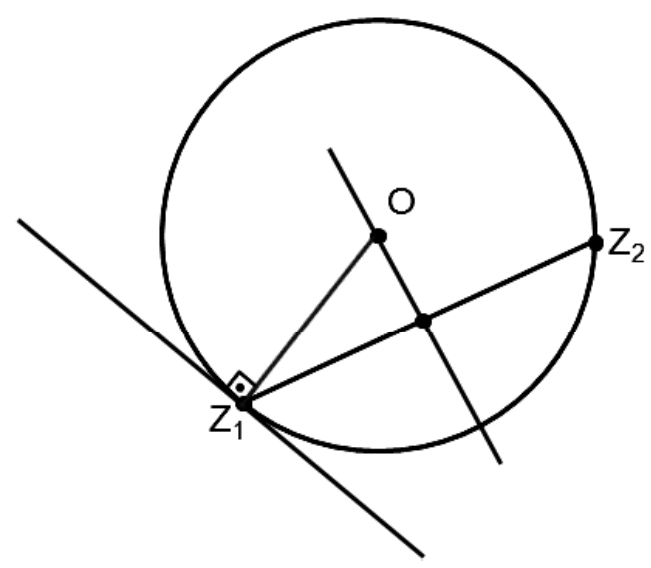

Figura 32. Retas no plano complexo, sendo $(\mathrm{O})$ origem do plano.

\section{Equação da reta determinada por $Z_{1}$ e $Z_{2}$}

Conhecendo os dois complexos, usamos a equação (1) e obtemos:

$$
Z+\frac{Z_{1} Z_{2} \bar{Z}}{R^{2}}=Z_{1}+Z_{2}
$$

Observa-se que a equação obtida é uma generalização da equação (2).

Equação da reta mediatriz determinada pelos pontos $Z_{1}$ e $Z_{2}$.

Essa reta passa pela origem e utilizando a equação (6) escrevemos:

$$
\mathrm{Z}\left(\overline{Z_{1}}-\overline{Z_{2}}\right)+\bar{Z}\left(Z_{1}-Z_{2}\right)=\left|Z_{1}\right|^{2}-\left|Z_{2}\right|^{2}
$$


Como os complexos possuem mesmo módulo, chega-se a:

$$
Z-\frac{Z_{1} Z_{2} \bar{Z}}{R^{2}}=0
$$

Equação da reta tangente passando por $Z_{1}$.

Usando a equação (8) e considerando que $\mathrm{Z}_{1}=\mathrm{Z}_{2}$, chegamos $\mathrm{a}$,

$$
Z+\frac{Z_{1}^{2}}{R^{2}}=2 Z_{1}
$$

4.6 Equações no plano complexo das retas notáveis do triângulo determinado por três números complexos distintos e não colineares $\mathrm{A}$, B e C

Para os casos abaixo, o circuncentro do triângulo está na origem do plano complexo.

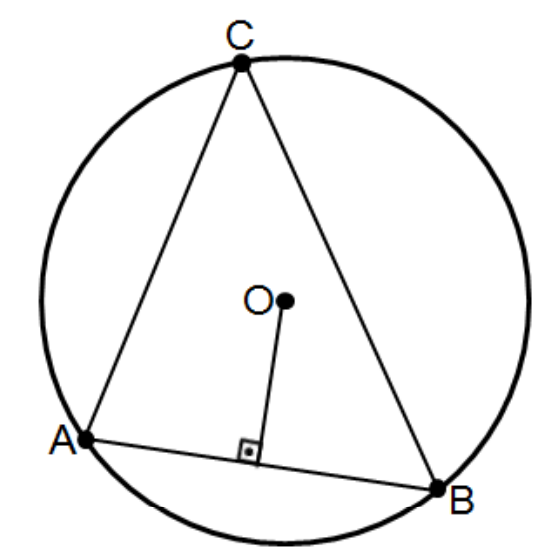

Figura 33. Triângulo $\triangle A B C$, que distam $\mathrm{R}$ do ponto (O).

Equações das três mediatrizes do triângulo $\triangle A B C$ :

Para a determinação destas equações foi utilizada a equação (9):

$$
\begin{aligned}
& z-\frac{B C z}{R^{2}}=0 \\
& z-\frac{A B z}{R^{2}}=0 \\
& z-\frac{A C z}{R^{2}}=0
\end{aligned}
$$

Vale lembrar que as coordenadas do circuncentro são verificadas nas três equações acima. 


\section{Equações das três retas suportes das medianas do triângulo $A B C$ :}

Como visto anteriormente, conhecendo dois complexos, podemos determinar a equação da reta utilizando a matriz, assim:

Reta passando pelo complexo A:

$$
z-\frac{(2 A-B-C) \bar{Z}}{2 \bar{A}-\bar{B}-\bar{C}}=\frac{\bar{A}(B+C)-A(\bar{B}+\bar{C})}{2 \bar{A}-\bar{B}-\bar{C}}
$$

De forma análoga obtemos as outras duas equações:

Reta passando pelo complexo B:

$$
z-\frac{(2 B-A-C) \bar{z}}{2 \bar{B}-\bar{A}-\bar{C}}=\frac{\bar{B}(A+C)-B(\bar{A}+\bar{C})}{2 \bar{B}-\bar{A}-\bar{C}}
$$

Reta passando pelo complexo C:

$$
z-\frac{(2 C-A-B) \bar{Z}}{2 \bar{C}-\bar{A}-\bar{B}}=\frac{\bar{C}(A+B)-C(\bar{A}+\bar{B})}{2 \bar{C}-\bar{A}-\bar{B}}
$$

As coordenadas do centróide satisfazem as três equações acima.

\section{Equação das três retas suportes das alturas do triângulo ABC}

Conhecendo um ponto e sabendo que ela é perpendicular a uma reta dada obtemos as seguintes equações, utilizando (5),

Reta passando por A e perpendicular a $\overleftrightarrow{B C}$ :

$$
z-\frac{B C \bar{z}}{R^{2}}=A-\frac{B C \bar{A}}{R^{2}}
$$

Reta passando por $\mathrm{B}$ e perpendicular a $\overleftrightarrow{A C}$ :

$$
z-\frac{A C \bar{z}}{R^{2}}=A-\frac{A C \bar{B}}{R^{2}}
$$

Reta passando por $\mathrm{C}$ e perpendicular a $\overleftrightarrow{A B}$ :

$$
z-\frac{A B \bar{z}}{R^{2}}=A-\frac{A B \bar{C}}{R^{2}}
$$

As coordenadas do ortocentro satisfazem as três equações acima. 


\subsection{Equações das três bissetrizes internas e das três bissetrizes externas do} triângulo determinado por três números complexos não colineares distintos $A^{2}, B^{2}$ e $C^{2}$

Para evitar o uso excessivo de raízes, os vértices do triângulo serão os complexos $A^{2}, B^{2}$ e $C^{2}$.

Considere o triângulo esquematizado na Figura 32, formado pelos complexos $A^{2}, B^{2}$ e $C^{2}$, e a circunferência circunscrita ao triângulo $A^{2} B^{2} C^{2}$, de raio $R^{2}$. Para as demonstrações adotamos como convenção dos valores, - $A C$ (o valor médio do arco $\widehat{A^{2} C^{2}}$ ) quando não tiver o complexo $B^{2}$ no arco, $+A C$ quando tiver com o complexo $B^{2}$ no arco. Isso vale para os outros valores médios.

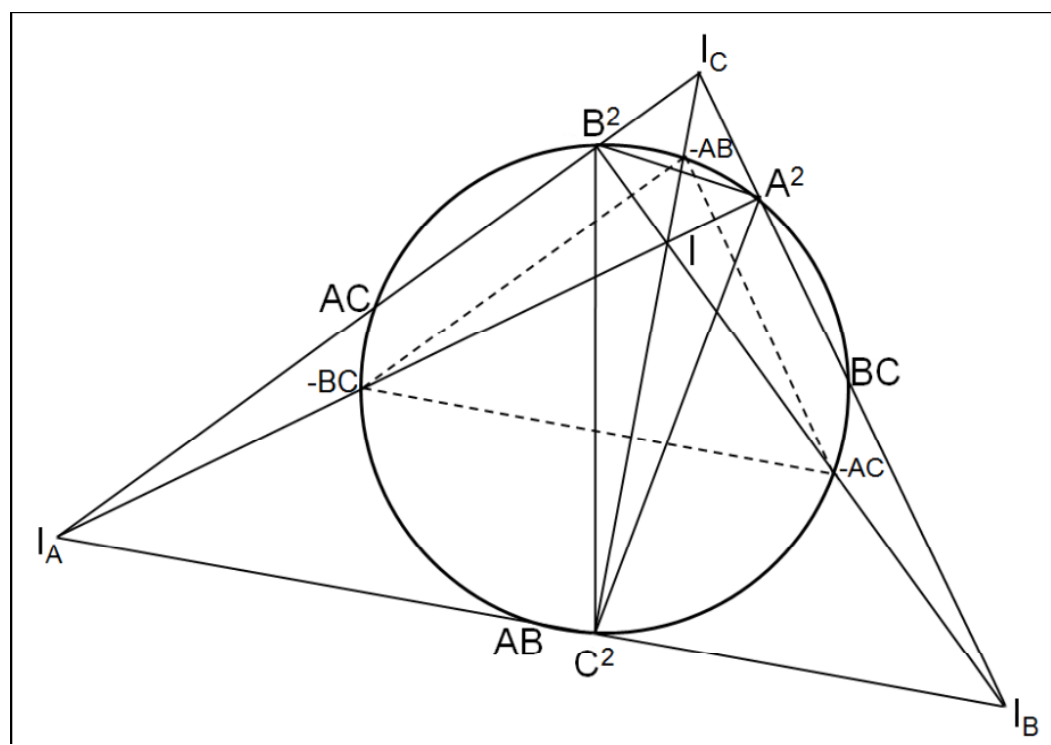

Figura 34. $I_{a}, I_{b}$ e $I_{c}$ são os exincentros do triângulo $A^{2} B^{2} C^{2}$.

\section{As equações das bissetrizes internas:}

A circunferência dos nove pontos do triângulo $I_{A}, I_{B}$ e $I_{C}$ circunscreve $O$ triângulo $A^{2}, B^{2}$ e $C^{2}$, assim a bissetriz interna do vértice $A^{2}$, corta o ponto médio do arco $\widehat{B^{2} C^{2}}$, que não contém $A^{2}$, esse ponto foi convencionado como $-\mathrm{BC}$. Assim, com esses dois pontos podemos escrever a equação da reta usando (8):

$$
Z-\frac{A^{2} B C \bar{Z}}{R^{4}}=A^{2}-B C
$$


Da mesma forma, escrevemos as outras equações:

$$
\begin{aligned}
& Z-\frac{B^{2} A C \bar{Z}}{R^{4}}=B^{2}-A C \\
& Z-\frac{C^{2} A B \bar{Z}}{R^{4}}=C^{2}-A B
\end{aligned}
$$

Os valores utilizados nas equações acima foram todos os convencionados com o sinal (-).

\section{As equações das bissetrizes externas:}

Da mesma forma que as equações das bissetrizes internas foram determinadas, as equações das bissetrizes externas serão determinadas. Nos casos abaixo, todos os valores médios dos arcos serão os convencionados (+). Com o auxílio da equação (8), obtemos:

$$
\begin{aligned}
& Z+\frac{A^{2} B C \bar{Z}}{R^{4}}=A^{2}+B C(14) \\
& Z+\frac{B^{2} A C \bar{Z}}{R^{4}}=B^{2}+A C(15) \\
& Z+\frac{C^{2} A B \bar{Z}}{R^{4}}=C^{2}+A B(16)
\end{aligned}
$$

Essas equações também poderiam ser obtidas utilizando a equação (5), pois a bissetriz interna é ortogonal à bissetriz externa.

\section{INCENTRO (I)}

O incentro (I) do triângulo $\Delta A^{2} B^{2} C^{2}$ é

$$
I=-(A B+A C+B C)
$$

Resolvendo o sistema de duas das equações (11), (12) e (13), obteremos as coordenadas do incentro $(I)$ do triângulo $\Delta A^{2} B^{2} C^{2}$ pois o incentro é a intersecção das 
três bissetrizes internas. Escolhendo (11) e (12), e isolando $\frac{\bar{Z}}{R^{4}}$, temos respectivamente:

$$
\begin{aligned}
& -\frac{\bar{Z}}{R^{4}}=\frac{A^{2}-B C-Z}{A^{2} B C} \\
& -\frac{\bar{Z}}{R^{4}}=\frac{B^{2}-A C-Z}{B^{2} A C}
\end{aligned}
$$

igualando,

$$
\begin{gathered}
\frac{A^{2}-B C-Z}{A^{2} B C}=\frac{B^{2}-A C-Z}{B^{2} A C} \\
Z(A-B)=A B^{2}+C B^{2}-B A^{2}-C A^{2}
\end{gathered}
$$

E fatorando de forma conveniente e isolando $Z$, temos,

$$
Z=-A B-A C-B C
$$

\section{EXCENTROS}

O ponto de intersecção entre as duas bissetrizes externas e a bissetriz interna do terceiro ângulo é chamado excentro. Esse ponto é o centro da circunferência que tangencia um lado do triângulo e as retas suportes dos outros dois lados, sendo essas circunferências chamadas de ex-circunferências. 


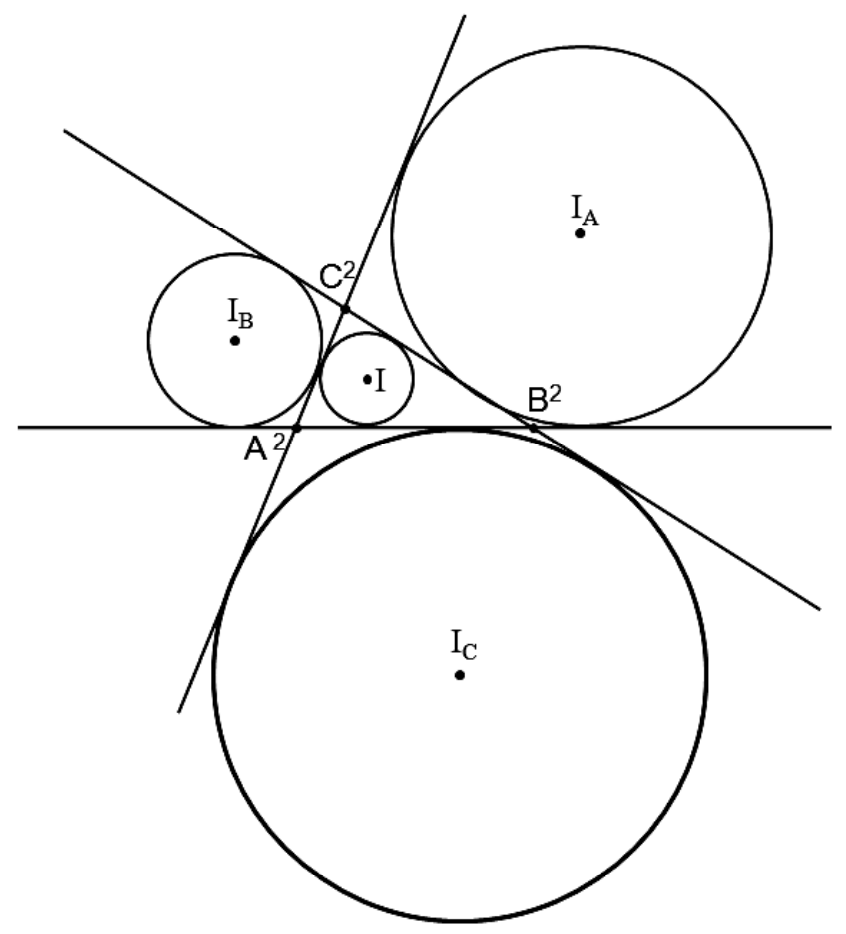

Figura 35. Ex circunferências do triângulo $\Delta A^{2} B^{2} C^{2}$.

O incentro do triângulo $\Delta A^{2} B^{2} C^{2}$ é o ortocentro do triângulo de vértices - $\mathrm{BC}$, AC e $-\mathrm{AB}$ pois o ortocentro é dado por $-(A B+A C+B C)$, e como vimos anteriormente, o ortocentro é determinado pela soma dos vértices.

Para determinarmos os complexos que representam os excentros do triângulo $\Delta A^{2} B^{2} C^{2}$, basta resolver as equações (13), (14) e (15), duas a duas. Como exemplo, toma-se (13) e (14) e isolando $\frac{\bar{Z}}{R^{4}}$, temos respectivamente:

$$
\begin{aligned}
& \frac{\bar{Z}}{R^{4}}=\frac{A^{2}+B C-Z}{A^{2} B C} \\
& \frac{\bar{Z}}{R^{4}}=\frac{B^{2}+A C-Z}{B^{2} A C}
\end{aligned}
$$

igualando

$$
\begin{gathered}
\frac{A^{2}+B C-Z}{A^{2} B C}=\frac{B^{2}+A C-Z}{B^{2} A C} \\
Z(A-B)=A B^{2}-C B^{2}-B A^{2}+C A^{2}
\end{gathered}
$$


64

e fatorando de forma conveniente e isolando Z, temos,

$$
Z=-A B+A C+B C
$$

Esse é o complexo é do $I_{c}$ :

$$
I_{C}=-A B+A C+B C
$$

Da mesma maneira se obtém os outros complexos dos excentro do triângulo $A^{2} B^{2} C^{2}$, que são:

$$
\begin{aligned}
& I_{A}=-B C+A B+A C \\
& I_{B}=-A C+A B+B C
\end{aligned}
$$

\subsection{Teorema de Feuerbach}

No ano de 1822, Feuerbach comprovou que a circunferência dos nove pontos tangencia internamente a circunferência inscrita e externamente as três excircunferências de um triângulo qualquer. A intersecção da circunferência inscrita e a circunferência dos nove pontos é chamada de ponto de Feuerbach.

Os complexos $A^{2}, B^{2}$ e $C^{2}$, distintos e não colineares, serão os vértices do triângulo, chamaremos de $R^{2}$ o módulo desses complexos, vale ressaltar que utilizaremos o triângulo na posição especial, ou seja, o circuncentro é a origem do plano complexo.

Iniciamos mostrando que as circunferências inscrita e a dos nove pontos são tangentes interiores (Figura 36). 
Prova: Basta calcular a distância entre o incentro $(I)$ e o centro $(N)$ da circunferência dos nove pontos.

$$
\begin{gathered}
d=|N-I| \\
d=\left|\frac{A^{2}+B^{2}+C^{2}}{2}+A B+A C+B C\right| \\
d=\frac{1}{2}\left|(A+B+C)^{2}\right| \\
d=\frac{1}{2} S_{1} \bar{S}_{1} \\
d=\frac{R^{2}}{2} \cdot \frac{S_{1} S_{2}}{S_{3}}
\end{gathered}
$$

em que

$$
\begin{gathered}
S_{1}=A+B+C \\
S_{2}=A B+A C+B C \\
S_{3}=A B C
\end{gathered}
$$

e o raio $r$ da circunferência inscrita,

$$
\frac{1}{2}\left(B^{2}+C^{2}-S_{2}+\frac{B C S_{1}}{A}\right)
$$

é o número complexo da intersecção da reta determinada por $B^{2} C^{2}$ cuja equação é:

$$
Z+\frac{B^{2} C^{2} \bar{Z}}{R^{4}}=B^{2}+C^{2}
$$

com a reta perpendicular à reta $\mathrm{B}^{2} \mathrm{C}^{2}$ pelo incentro (I), cuja a equação é:

$$
Z-\frac{B^{2} C^{2} \bar{Z}}{R^{4}}=-S_{2}+\frac{B C}{A} S_{1}
$$

Portanto, $r=\left|\frac{1}{2}\left(B^{2}+C^{2}-S_{2}+\frac{B C S_{1}}{a}\right)+S_{2}\right|=\frac{1}{2}\left|S_{1} S_{2}-S_{3}\right|$

o que mostra que $d=\frac{R^{2}}{2}-r$, e as circunferências são tangentes interiormente. 


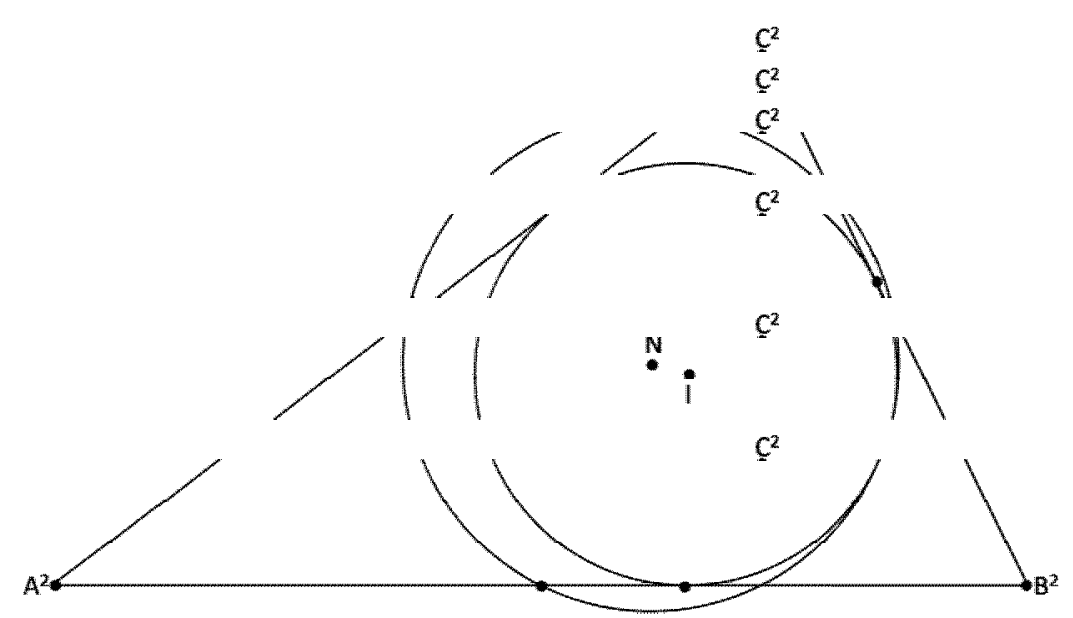

Figura 36. Tangência interna entre as circunferências inscrita e A dos nove pontos.

Para demonstrar que as ex-circunferências são tangentes exteriores à circunferência dos nove pontos, basta calcular a distância entre os centros e calcular os raios das ex-circunferências, da mesma forma que no caso da tangente interna.

TEOREMA 4.8.1 - A condição necessária e suficiente para que três números complexos $Z_{1}, Z_{2}$ e $Z_{3}$ distintos e não colineares sejam vértices de um triângulo equilátero é:

$$
Z_{1}^{2}+Z_{2}^{2}+Z_{3}^{2}=Z_{1} Z_{2}+Z_{1} Z_{3}+Z_{2} Z_{3}
$$

Corolário 4.8.1 - Números complexos distintos unitários e não colineares, cuja soma é nula, são vértices de um triângulo equilátero inscrito no círculo unitário.

Corolário 4.8.2 - Caso as três raízes complexas da equação do terceiro grau com coeficientes complexos,

$$
z^{3}-3 p z^{2}+3 q z-r=0
$$

sejam números complexos distintos e não colineares, então o número complexo $p$ é o centróide do triângulo e a condição necessária e suficiente para o triângulo determinado pelas raízes ser equilátero é que $p^{2}=q$. 


\section{9 Teorema de Napoleão}

O teorema de Napoleão diz: se triângulos equiláteros são construídos sobre os lados de um triângulo, então os centróides dos três triângulos equiláteros formam um triângulo equilátero; analogamente, conclui-se que os centros dos triângulos eqüiláteros desenhados internamente aos lados de qualquer triângulo também definem um triângulo equilátero.

Esse teorema é atribuído ao imperador da França Napoleão Bonaparte (1769 - 1821), que foi um talentoso estudante de matemática e mantinha contato com grandes matemáticos da sua época. No entanto, há quem duvide que seja ele o autor do teorema que leva o seu nome.

Quando triângulos equiláteros são construídos externamente aos lados de um triângulo $A B C$, os centróides dos três triângulos equiláteros são vértices de um triângulo equilátero.

O baricentro do triângulo $A B C$ é $\frac{1}{3}(A+B+C)$ e então os três números complexos são:

$$
\begin{gathered}
X=\frac{1}{3}\left[A+C+\left(A-W^{2}(C-A)\right)\right]=\frac{1}{3}\left[\left(2+W^{2}\right) A+\left(1-W^{2} C\right)\right] \\
Y=\frac{1}{3}[A+B+(A-W(B-A))]=\frac{1}{3}[(2+W) A+(1-W) 6] \\
Z=\frac{1}{3}[B+C+(B-W(C-B))]=\frac{1}{3}[(2+W) B+(1-W) C]
\end{gathered}
$$

Em que $w^{2}+w+1=0$, são os baricentros dos três triangulares e como

$$
z-x=-w^{2}(y-x)
$$

então o triângulo $\mathrm{XYZ}$ é um triângulo equilátero. 


\section{CONCLUSÕES}

Nesta dissertação, fizemos um breve passeio pela geometria. No primeiro capítulo demonstramos alguns teoremas clássicos, utilizando a própria geometria como ferramenta. No capítulo dois, realizamos uma abordagem algébrica, utilizando algumas funções específicas e verificamos que os pontos notáveis são pontos de máximo ou de mínimo. No capítulo três, entramos na época de René Descartes (1596 - 1650), também conhecido como Renatus Cartesius (seu nome em latim) que sugeriu a fusão da álgebra com a geometria, introduzindo as coordenadas, que hoje levam o seu nome (Sistema Cartesiano) e capturam toda a geometria clássica, transformando-a em números e equações, dando assim à Matemática outra dinâmica, permitindo estudos mais gerais em relação à geometria clássica. Por fim, no capítulo quatro, introduzimos as variáveis complexas, o plano de Argand-Gauss, Jean Robert Argand (1786 - 1822) matemático amador suíço, que teve seu trabalho citado, no entanto, o seu nome nunca apareceu no livro, após algum tempo recebeu o reconhecimento pelo seu trabalho, já Johann Carl Friedrich Gauss (1777 - 1855), conhecido como "o príncipe da matemática", foi o primeiro matemático a dar uma interpretação geométrica aos números complexos, e teve importantes participações em diversas áreas da matemática. Os números complexos estão relacionados com o plano cartesiano, porém, com a introdução de uma nova ferramenta, pois no caso do plano cartesiano, não é possível fazer a divisão entre vetores, com esse plano complexo, é possível fazer a divisão entre números complexos.

Comparando as várias abordagens, podemos afirmar que com a compreensão dos números complexos, paradoxalmente simplifica-se a resolução de problemas de geometria plana e a solução de equações polinomiais. 
O domínio da ferramenta dos números complexos é fundamental para a interligação dos vários conteúdos do currículo de matemática do Ensino Médio.

Com o advento dos números complexos, podemos algebrizar vetores, de maneira que esta algebrização auxilia diversos campos da Matemática, bem como os das outras ciências.

Vale lembrar que, pretendo aplicar essas relações e mostrar os resultados principalmente a dos números complexos em cursos e mini cursos para os "meus" alunos do Ensino Médio. 


\section{REFERÊNCIAS}

1. SÃO PAULO. Secretaria do Estado da Educação. Saresp 2011. Disponível em: <http://saresp.fde.sp.gov.br/2011/Pdf/Relat\%C3\%B3rio_Pedag\%C3\%B3gico_LP_ Mat_3\%C2\%BA\%20EF_2011.pdf> Acesso em 13 de novembro de 2012.

2. ÍNDICE DE DESENVOLVIMENTO DA EDUCAÇÃO BÁSICA (IDEB). Disponível em <http://ideb.inep.gov.br/Site/>. Acesso em: 25 de novembro de 2012.

3. SÃO PAULO (Estado). Secretária da Educação, Coordenadoria de Estudos e Normas Pedagógicas. Proposta Curricular para o ensino de Matemática:ensino fundamental - ciclo II e ensino médio. Coord. Maria Inês Fini. - São Paulo : SEE, 2008.

4. HIRATSUKA, P.I. O lúdico na superação de dificuldades no ensino de geometria. Educação em Revista, Marília, 2006v.7, n.1/2, p. 55-66.

5. MORASCO JUNIOR, O.C.; GAMA, R.P. Sistema de Avaliação do Rendimento Escolar do Estado de São Paulo (SARESP): ações e repercussões no ensino de matemática. XIII CIAEM-IACME, Recife, Brasil, 2011.

6. SERRAZINA, M. L.; PONTE, J. P.; OLIVEIRA, I. Grandes temas matemáticos. Em: A Matemática na Educação Básica. Lisboa: Ministério da Educação Básica, 1999. p. 41- 91.

7. COXETER, H. S. M.; GREITZER, S.L. Geometry revised. Yale University, 1967, 193 p.

8. Introduction to Geometry, 2nd ed., John Wiley \& Sons, New York, 1969, 469 p..

9. DODGE, C.W. Euclidean geometry and transformations. Addison-Wesley Publishing Company, Inc. Phillipines, 1972, 295 p.

10. NELSEN, R.B. Proofs without words. The mathematical association of America (Incorporated), 1993, $128 \mathrm{p}$.

11. HAHN, L. Complex Numbers and Geometry. Washington: The Mathematical Association of America, 1994.

12. LARSON, L.C. Problem-Solving Through Problems. Springer-Verlag New York Inc, 1983, 333 p. 